\title{
Do I still like myself? Human-robot collaboration entails emotional consequences
}

\author{
Patrick P. Weis ${ }^{*} \&$ Cornelia Herbert \\ Institute of Psychology and Education, Ulm University, Ulm, Germany \\ * Current affiliaton: Julius Maximilian University, Wuerzburg, Germany
}

\begin{abstract}
Author Note
This research was funded by the budgetary resources of the Department of Applied Emotion and Motivation Psychology at Ulm University. We have no conflicts of interest to disclose. This study was conceptualized and designed by $\mathrm{CH}$ and PPW, programmed by PPW, data was collected and analyzed by PPW, the manuscript was written by $\mathrm{CH}$ and PPW. Correspondence concerning this article should be addressed to Patrick P. Weis, Julius Maximilian University, Department of Psychology (III), Roentgenring 11, 97070 Wuerzburg, Germany, phone: +49 931 3186456, e-mail: patrick.weis@ uni-wuerzburg.de.
\end{abstract}

(C) 2021. This manuscript version is made available under the CC-BY-NC-ND 4.0 license http://creativecommons.org/licenses/by-nc-nd/4.0/.

The final version of this manuscript has been published in Computers in Human Behavior at https://doi.org/10.1016/j.chb.2021.107060 


\begin{abstract}
Investigating emotional processes has been vital for understanding human-human interaction. Specifically, emotional concepts of oneself and interaction partners shape interaction style and are associated with mental health and cognitive performance. Whether these concepts are equally relevant in humanrobot interaction (HRI) has not been investigated. Here, we measured emotional concepts before and after collaboration with a telepresent robot described as (a) able, (b) unable to experience emotions, or (c) autonomous without reference to emotions, compared to a (d) control condition without human-robot collaboration. Emotional concepts were measured with the affective His-Mine-Paradigm (aHMP) in which participants were asked to affectively evaluate pronoun-noun-pairs related to themselves (e.g., "my victory") or the robot (e.g., "its victory"). Results indicated that (1) the aHMP can be validly used in HRI contexts, (2) emotional self-concept got less positive after interacting with "emotionless" robots, and emotional robot-concept got more positive after interacting with (3) "autonomous" or (4) "emotional" robots. Results suggest that beliefs about and interactions with telepresent robots can change emotional concepts which themselves are associated with well-being, performance, and interaction style. In sum, we report emotional consequences of HRI and argue that such consequences should receive more attention in future research and HRI design.
\end{abstract}

Keywords: Human-robot interaction; cognitive offloading; emotions; telepresence; self 


\section{Introduction}

\subsection{Overview}

In modern society, having emotional contact with robots or virtual agents is common. The first children who grew up with computers - in the 80s — referred to humans as "emotional machines" (Turkle, 2012, p. 30). Labelling people as emotional thus contrasted them with the remaining machines that were unable to experience emotions. These boundaries have been blurred in the 90 s when machines like Furby (Hasbro Inc., Rhode Island, USA) started expressing emotions (e.g., "I am scared") and were object of a child's empathy (e.g., "when the batteries are removed [...] the Furby forgets its life"; Turkle, 2012, p. 41). Since then, numerous case reports indicated that interactions with robots designed for emotional contact were indeed described as emotional, though not necessarily as emotional as interactions with humans (Turkle et al., 2006). Experimental investigations bolster these reports. For example, watching a robot getting tortured was shown to increase negative affect and physiological arousal when compared to watching a non-torture control video (Rosenthal-von der Pütten et al., 2013). Similarly, observing non-verbal robot behavior was found to boost positive affect as compared to observing a robot lacking non-verbal behavior (Rosenthal-von der Pütten et al., 2018). Interacting with robots thus seems to have emotional consequences for the human interaction partner. This complements the extensive emotion-related research on the robot side of the interaction (i.e., designing emotional features like emotion recognition or expression; e.g., Bartneck, 2003; Beck et al., 2010; Breazeal, 2003; Hegel et al., 2010).

Here, we build on these studies to investigate a specific subcomponent of emotional consequences for the human interaction partner: consequences for the emotional self- and other-concepts. Consequences for emotional self- and other-concepts are particularly relevant as they are linked to well-being and mental health (e.g.; Mezulis et al., 2004; Winter et al., 2015)—a link possibly mediated by changes in structural plasticity in the prefrontal cortex (Lumma et al., 2018). In particular, we focus on two preregistered research goals. First, we strive to confirm that the presently used paradigm (the affective His-MineParadigm; Herbert, Herbert, Ethofer, et al., 2011; Herbert, Pauli, et al., 2011; see section 2.3.1) can be 
validly used to measure the emotional self- and other-concepts in a novel context. This novel context consists of interactions between humans and non-human robots rather than human agents (cf. H1-1 and H12). Second, we strive to build on that validation and use the aHMP to investigate whether beliefs about and interactions with robots can change the emotional self-other (here: robot)-concepts (cf. H2-1 and H22). Gaining a better understanding of such emotional consequences of human-robot interaction seems imperative in the highly technologized worlds of today and tomorrow. Note that we use a telepresent rather than a physically copresent robot in the current investigation (implications are further discussed in section 1.4).

\subsection{Emotional Self- and Other-Concept}

How people see themselves is not merely influencing their thoughts but also impacts behavior and well-being (Diener \& Diener, 1996). This is reflected by the self-positivity bias: people see themselves positively-more positively than reality warrants. This tendency of seeing oneself in a positive light and of associating positive information with oneself is substantial (Mezulis et al., 2004) and likely promoting mental health (Taylor \& Brown, 1988, 1994). Consequentially, a self-positivity bias is rather the norm than the exception in healthy subjects (Diener \& Diener, 1996; Mezulis et al., 2004) and crucially, positive affective states such as being in an romantic relationship (e.g., Meixner \& Herbert, 2018) can even extend this self-positivity bias to include other humans. In contrast, a decreased self-positivity bias is associated with depression, anxiety, and attention-deficit/hyperactivity disorder (Mezulis et al., 2004), and also with personality and its disorders (e.g., Winter et al., 2015). How people see themselves can also impact cognitive performance. For example-according to stereotypes-women perform worse in math than men (Spencer et al., 1999). This stereotype threat leads to decreased performance but, crucially, performance differences vanished in an experimental setting once participants were informed that no gender differences would exist for the task at hand (Spencer et al., 1999). Thus, although the self-concept as a whole is supposed to be relatively stable (Epstein, 1973), specific subcomponents like a negative task-relevant selfconcept can be altered relatively quickly. The dynamic nature of parts of the self-concept is also illustrated by the dynamic nature of state self-esteem (Heatherton \& Polivy, 1991). In sum, a positive self-concept is 
desirable because it is linked to well-being and increased performance but can be subject to short-term change elicited by self-compromising situations.

How people see themselves is also intricately linked to how people see others. In fact, establishing close relationships might encompass including the other in the self (self-expansion; Aron \& Aron, 1996). Accordingly, participants needed longer to decide whether a trait described themselves if their spouse did not share versus shared that trait (Aron et al., 1991). Furthermore, in an experimental study investigating participants in a romantic relationship, the self-positivity was shown to expand to a self-and-otherpositivity-bias specifically for participants in a romantic relationship as compared to singles (Meixner \& Herbert, 2018). Unsurprisingly, how we see another agent also impacts our interactions with that agent. This impact — but also the close links between other- and self-concept-is illustrated by the seminal fourcategory model of adult attachment (Bartholomew \& Horowitz, 1991; Bowlby, 1979): For example, positive self- and other-concepts are associated with a secure relationship style that allows intimacy while negative self- and other-concepts are associated with a fearful relationship style leading to avoidance of intimacy. Underlining the relevance of the other concept for human-robot interaction, attachment theory has already been used to derive guidelines for social robot design (Dziergwa et al., 2018). Taken together, we argue that changes in emotional self- and other-concepts are likely during interactions with robots and are relevant because they are linked to mental well-being, performance, and interaction style.

\subsection{Cognitive Offloading and its Consequences}

Solving problems in concert with fellow humans, robots, non-embodied computers like smartphones, or analog aids like pen and paper to outsource cognitive processing is an abundant activity in modern society (cognitive offloading [CO], Risko \& Gilbert, 2016; for additional reviews , also see Clark, 1999; Hutchins, 1995; Ifrah, 2001; Kirsh, 2013). In contrast to the less focused interactions with robot companions like Furby, $\mathrm{CO}$ is centered on task-relevant outcomes like providing the solution to an arithmetic or navigation problem. It is known that people can adaptively adjust how frequently they engage in $\mathrm{CO}$ depending on the situation (e.g., depending on the time costs of engaging in $\mathrm{CO}$; W. D. Gray et al., 2006; Storm et al., 2017; or on whether speed or accuracy is prioritized; Weis \& Wiese, 2019). However 
sometimes people fail to adjust adaptively because of inaccurate metacognitive judgements like wrongly estimating own cognitive ability such as underestimating own memory (Gilbert, 2015; Touron, 2015). Current research thus provides a successively clearer picture about what makes people engage in CO.

But apart from the underpinnings of engaging, it is also vital to the hybrid societies of today and tomorrow to understand the consequences of $\mathrm{CO}$ to eventually learn how to promote or prevent them (i.e., help people make better decisions whether or not to engage in $\mathrm{CO}$ ), an understanding that is currently mostly lacking (compare Risko \& Gilbert, 2016, p. 685). That consequences do exist is highly likely as illustrated by the following examples. Firstly, it was shown that $\mathrm{CO}$ can alter the way stored information is represented (Fu, 2011): Biological memory consists of a multitude of active processes and so, for example, similar items can be grouped together to reduce representational complexity (Nosofsky, 1992) which then, however, leads to decision biases favoring dissimilar items (Fu, 2011). Such biases are absent for passive external information storages $(\mathrm{Fu}, 2011)$. Secondly, it was shown that reliance on highly timeefficient $\mathrm{CO}$ behavior reduces preoccupation with the task. Decreased preoccupation time can hinder the user's understanding of the task which subsequently negatively impacts performance on similar but novel tasks (O’Hara \& Payne, 1998). Lastly, it has been shown that searching the internet to answer trivia questions inflated how people estimated their independent (i.e., without the help of internet search) ability to answer other trivia questions (Fisher et al., 2015). The study has been conceptually replicated using cognitive self-esteem ratings instead of the task-specific estimation of own trivia knowledge (Hamilton \& Yao, 2018) which strongly suggests consequences of CO for the self-concept. The intricate way in which selfconcept and CO are linked is illustrated by another finding from Hamilton and Yao (2018): When participants owned the device used for CO (e.g., a smartphone), cognitive self-esteem ratings were inflated in comparison to when participants used a non-owned but equally well performing device (e.g., another smartphone). To conclude, we argue that significant consequences of $\mathrm{CO}$ do exist and that the importance and ubiquity of $\mathrm{CO}$ in modern society warrants further examination of these consequences. 


\subsection{Environments used for Cognitive Offloading ${ }^{1}$}

After defining $\mathrm{CO}$ and arguing about the importance of researching its consequences for the offloader, we want to emphasize that both the implementation of $\mathrm{CO}$ and likely also its consequences are shaped by the offloading environment. In general, a human's environment frequently affords a wide variety of possibilities to offload one's cognition onto: from inanimate options like computers to animate options like humans, from low-tech options like paper to high-tech options like 3D drawing in a virtual environment, from simulated options like chatbots to physically present options like certain robots. Current research is starting to develop insights into how these fundamentally different options might affect how we behave during interactions (e.g., Biocca, 1997; Duffy, 2003; Wiese et al., 2017). For example, it is known that humans behave differently when they believe the interaction partner to possess a mind, a belief that can be likely shaped by both appearance and verbal introduction of the interaction partner (Wiese et al., 2012).

Since the current investigation necessitated manipulation of mind ascription-experiencing emotions has been defined as a subcomponent of the mind (H. M. Gray et al., 2007) —we used an already established approach from Wiese and colleagues (2012): We decided for an offloading option with a telepresent ${ }^{2}$ robot $^{3}$ in combination with differing verbal introductions of that robot. It should be noted that results obtained from interaction with a telepresent robot do not necessarily match with other forms of interactions. Accordingly, a review found that physically copresent robots are more persuasive, receive more attention, and are perceived more positively ( $\mathrm{Li}, 2015)$, and can also be associated with a better interaction-mediated task performance (Bartneck, 2003), than their telepresent counterparts. On the one hand, these findings emphasize differences resulting from moderate alterations of the offloading environment. On the other hand, the findings also suggest effect sizes to be overall bigger when employing copresent rather than telepresent agents in one's offloading environment, which puts the present study design

${ }^{1} \mathrm{We}$ want to thank the anonymous reviewer for inspiring that section

${ }^{2}$ Rather than physically copresent in the same room

${ }^{3}$ Which is made out of metal and plastic parts rather than virtual and created by an algorithm (Dautenhahn, 1998) 
at the conservative end. In other words, any potential effects found in the current study might be more pronounced during interactions with copresent rather than telepresent agents. Interestingly, the same review found no differences between interactions with virtual agents vs. robots, which suggests that results of the present study might generalize to interactions with a wide variety of telepresent agents in addition to prototypical robots.

\subsection{Current Investigation}

Previous research has illustrated that the context (e.g., using an owned vs. non-owned smartphone) in which CO takes place can alter the cognitive self-concept (Hamilton \& Yao, 2018). Here, we aim to extend these findings and explore whether the context in which CO takes place can also alter the emotion$a l$ self- and other-concepts. The study will thereby complement the rather well-researched area of designing emotions in robots (e.g., Bartneck, 2003; Beck et al., 2010; Breazeal, 2003; Hegel et al., 2010) and increase the rather limited understanding (compare, e.g. Rosenthal-von der Pütten et al., 2013, 2018; Turkle et al., 2006) of the emotional consequences of solving tasks in concert with - in this case, telepresent-robots.

\subsubsection{The His-Mine-Paradigm}

In the preset study, to measure the emotional self- and other concept, the affective His-Mineparadigm (aHMP; Herbert, Herbert, Ethofer, et al., 2011; Herbert, Herbert, \& Pauli, 2011; Herbert, Pauli, et al., 2011) is used. In the aHMP, words are used in an attempt to measure how self- and other-referential information and emotion processing interact and how self-referential information is discriminated from other-referential information. In the present instance of the aHMP, participants needed to evaluate nouns preceded by a self- or other-referential pronoun (e.g., "my victory" or "its victory"). A self-positivity bias would then be indicated if participants rated positive self-referential words both faster and more positively than positive other-referential words (as found for example in previous behavioral studies using the aHMP; Meixner \& Herbert, 2018; Weis \& Herbert, 2017). Similarly, a positive other-concept is conveyed 
by a faster and more positive evaluation of other-referential words (as found for participants in a romantic partnership vs. singles; Meixner \& Herbert, 2018).

\subsubsection{Hypotheses}

The present study is designed to investigate whether (H1) the aHMP can be validly used to measure emotional self- and other-concepts in a novel context: interactions with robot rather than human agents. To do so, we aim to replicate the existence of the self-positivity bias (i.e., preference for positive information related to the self compared to positive information related to another agent). So far, the selfpositivity bias has only been shown in human-human but not in human-robot interaction contexts. We additionally explore individual difference measures related to alexithymia, depression, and inclusion of the other in the self to confirm construct validity. If validated, the aHMP can then be used to research emotional consequences of human-robot interaction. Specifically, it is investigated whether (H2) the context in which the interactions take place - in particular, the emotional framing of a robot interaction partner as being able or unable to experience emotions - impacts the emotional self-and other-concept. Emotional framing was used for two reasons. First, framing has been validly used to alter beliefs about and interaction behavior with robot agents in earlier research (e.g., Weis \& Wiese, 2020; Wiese et al., 2012). Second, it is known that beliefs about emotional capacities of a second interaction partner are highly relevant for emotional and cognitive processing of the first interaction partner. Specifically, beliefs about emotional capacities are linked to mind perception (H. M. Gray et al., 2007) and can lead to more intense interaction experiences (Waytz et al., 2010), evoke additional cognitive processes like social desirability considerations (Waytz et al., 2010), and might decrease dehumanization (Haslam, 2006) of the interaction partner. Dehumanization is linked to negative emotional consequences (Baumeister et al., 1995; Tangney et al., 1996) and can therefore be deemed undesirable. Hypotheses were preregistered via the Open Science Foundation at osf.io/dxrvw ${ }^{4}$.

${ }^{4}$ We changed the factor names. "Cognitive interaction" is now called "robot framing" and "pronoun" is now called "possessive determiner". 
H1 The affective His-Mine-Paradigm can be used to replicate the previously reported self-positivity bias in a human-robot context rather than the typical human-human interaction context. In particular, before any kind of interaction with or emotion-related description of the robot, participants are hypothesized to exhibit a faster (H1-1) and more positive (H1-2) affective evaluation of self-related in comparison to robot-related words.

H2 The framing of a robot interaction partner differentially impacts the emotional self- and the emotional robot-concept. In particular, it is hypothesized that changes in affective evaluation from before to after engaging in cognitive offloading with a robot agent regarding how quickly (H2-1) and how positively (H2-2) participants rate self- and robot-related words differ depending on the emotional framing of the robot.

\section{Methods and Materials}

\subsection{Participants}

In total, 358 participants who reported to be fluent in English were recruited via Amazon Mechanical Turk (www.mturk.com). Data collection stopped once the preregistered sample size of 240 (four groups à 60) participants was reached after the preregistered exclusion criteria had been applied. Applying these criteria led to the exclusion of 24 participants who failed the attention check, i.e. failed to name the current year, and 94 participants who were not able to correctly select the instruction for the arithmetic task ("Subtract amount of gray from amount of black dots") out of five answer options at the end of the experiment or who stated to not have associated the possessive determiner "its" with the robot TRM-E either in the affective his-mine task before or after the arithmetic problem solving task despite several prompts to do so. Lastly - and beyond preregistered criteria-, we excluded 9 participants due to a large proportion of extremely fast or slow responses (for details, see section Data Cleaning). After these additional exclusions, a final sample of 231 participants (91 female, 1 diverse, 1 preferred not to disclose; mean age: 37.5 , age range: 18 to 73 ) was used for analyses. The sample size is in accordance with an a priori power analysis for a 3-way interaction effect $\left(f=0.10, \alpha=0.05,1-\beta=0.95, r_{\text {repeated measures }}=0.6\right.$; for 
details, see section Analyses). All participants gave informed consent prior to participation and were compensated with USD 3.33. This research complied with the tenets of the Declaration of Helsinki and was approved by the Ethics Committee at the local university.

\subsection{Apparatus}

Participants were running the experiment from their own personal computers; no smartphones were allowed. The experiment was presented using the well-established psychological testing software Inquisit Web (version 6.1; Millisecond Software, www.millisecond.com). Stimulus presentation scaled with screen size.

\subsection{Tasks}

During the main part of the experiment, participants had to first engage in affective his-mine-tasks. Subsequently, participants were to solve arithmetic problems. Lastly, participants again engaged in affective his-mine-tasks. For more details on the procedure, see Design and Procedure.

\subsubsection{Affective His-Mine-Task}

In the current implementation of the aHMP, participants were to rate the valence of an English word compound consisting of a possessive determiner ("my" or "its") and a noun (e.g., "strength"). Participants were instructed to relate compounds with the possessive determiner "my" to themselves and compounds with the possessive determiner "its" to the robot TRM-E (for details on the robot, see Design and Procedure: Robot Framing). Ratings could be positive (right arrow key press), neutral (down arrow key press), or negative (left arrow key press). Participants were asked to rely on their gut feelings for the rating and to rate as quickly and accurately as possible. Compounds were presented in capital letters vertically extending across $5 \%$ of the participant's vertical screen size. The task including trial timing is illustrated in Figure 1.

The nouns used in the affective his-mine-task were English translations of German nouns extracted from the revised version of the Berlin Affective Word List (BAWL-R; Võ et al., 2009) based on the following rules. First, the word is a noun. Second, the word represents no emotion as this would heavily 
promote anthropomorphizing (e.g., "Liebe", Engl. "Love", was excluded). Third, following the same reasoning, the word is not tightly related to human body or human culture (e.g., "Heilung", Engl. "healing", or "Urlaub", Engl. "vacation", were excluded). Lastly, the word can be meaningfully paired with a possessive determiner (e.g., "Sonne”, Engl. "sun", was excluded). From the remaining words, we chose the 32 words with positive valence (average valence $>0.7$ on a scale from -3 to 3 ) that had the lowest imaginability ratings (e.g., "Kirsche", Engl. "cherry", was excluded; see Table S1 for the full list). German rather than English word norms were used to facilitate word-wise comparison with future studies in German. Valence ("Is the following word associated with negative or positive emotions for you?") and imageability ("Does the following word evoke a clear mental image in your mind?") ratings of the English words were acquired from thirty participants on Amazon Mechanical Turk and are reported in Table S1.

\section{Figure 1}

Affective His-Mine Task

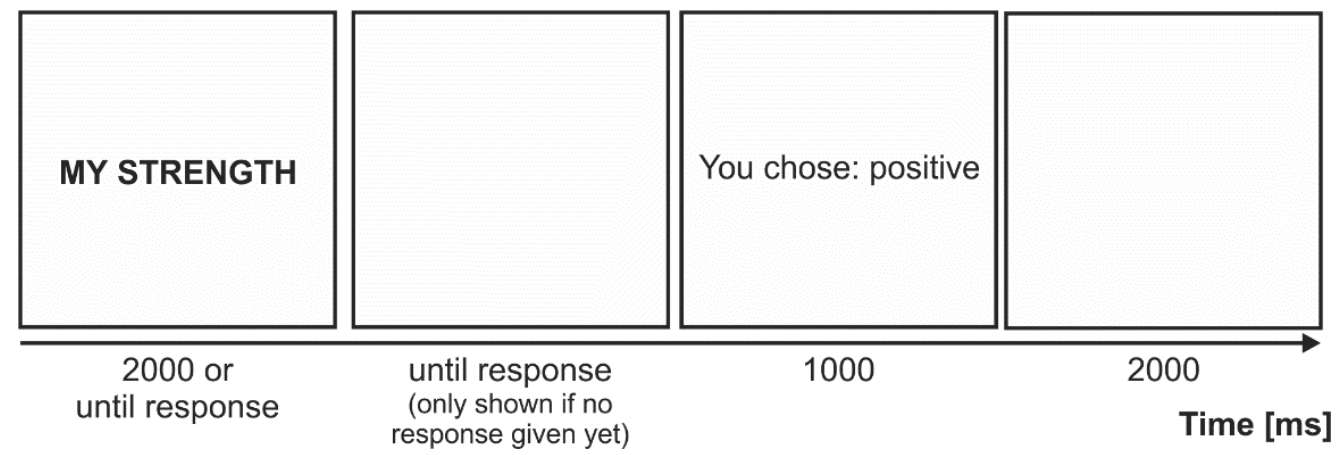

Note. At the beginning of each trial, a compound consisting of a possessive determiner and a noun was presented for $2000 \mathrm{~ms}$ or until participants indicated their evaluation via keypress. Immediately after providing the evaluation, participants received feedback regarding which key they pressed. Between trials, a blank screen was presented for 2000 ms. Stimuli are not drawn to scale. Sample trials are available at https://youtu.be/kJOoKemAcck. 


\subsubsection{Arithmetic Problem Solving Task}

In the arithmetic problem solving task, dots were presented on screen and participants were to subtract the amount of gray from the amount of black dots. Crucially, participants could either solve each arithmetic problem on their own by selecting one out of four numeric answer options or - in some but not

in other experimental conditions (see Design and Procedure: Emotional Framing)—seek support from a telepresent robot and select the agent rather than a numeric answer option. After selecting a numeric answer option (i.e., solving the problem on their own) or the robot (i.e., seeking support), the given answer was presented in the middle of the screen. The task including trial timing is illustrated in Figure 2.

For the arithmetic problems (compare Figure 2f), a total of 36 stimuli were created using an image manipulation software that allowed spatial manipulation of equally sized gray and black dots. Each stimulus contained either nineteen or twenty dots, with nine possible numerical differences of black relative to gray dots: $-4,-3,-2,-1,0,1,2,3$, or 4 . To create the 36 stimuli, one stimulus per numerical difference value (i.e., 9 base stimuli) was created first. The remaining 27 stimuli were created by mirroring the base stimuli on the horizontal axis and then mirroring base and mirrored stimuli on the vertical axis. To represent the robot, an image depicting the robot KISMET (developed at MIT, USA; Breazeal \& Scassellati, 1999) was used. The robot was of mechanistic appearance and the image was obtained based on a search for "mechanistic robot" using Google. Mechanistic instead of humanoid robots were chosen to decrease the likelihood of attributions of human-likeness. The picture was cropped to $400 \times 400$ pixels. The robot was named TRM-E. The combination of random letters and a special character was used to highlight the robots' machine-likeness. 


\section{Figure 2}

\section{Arithmetic Problem Solving Task}

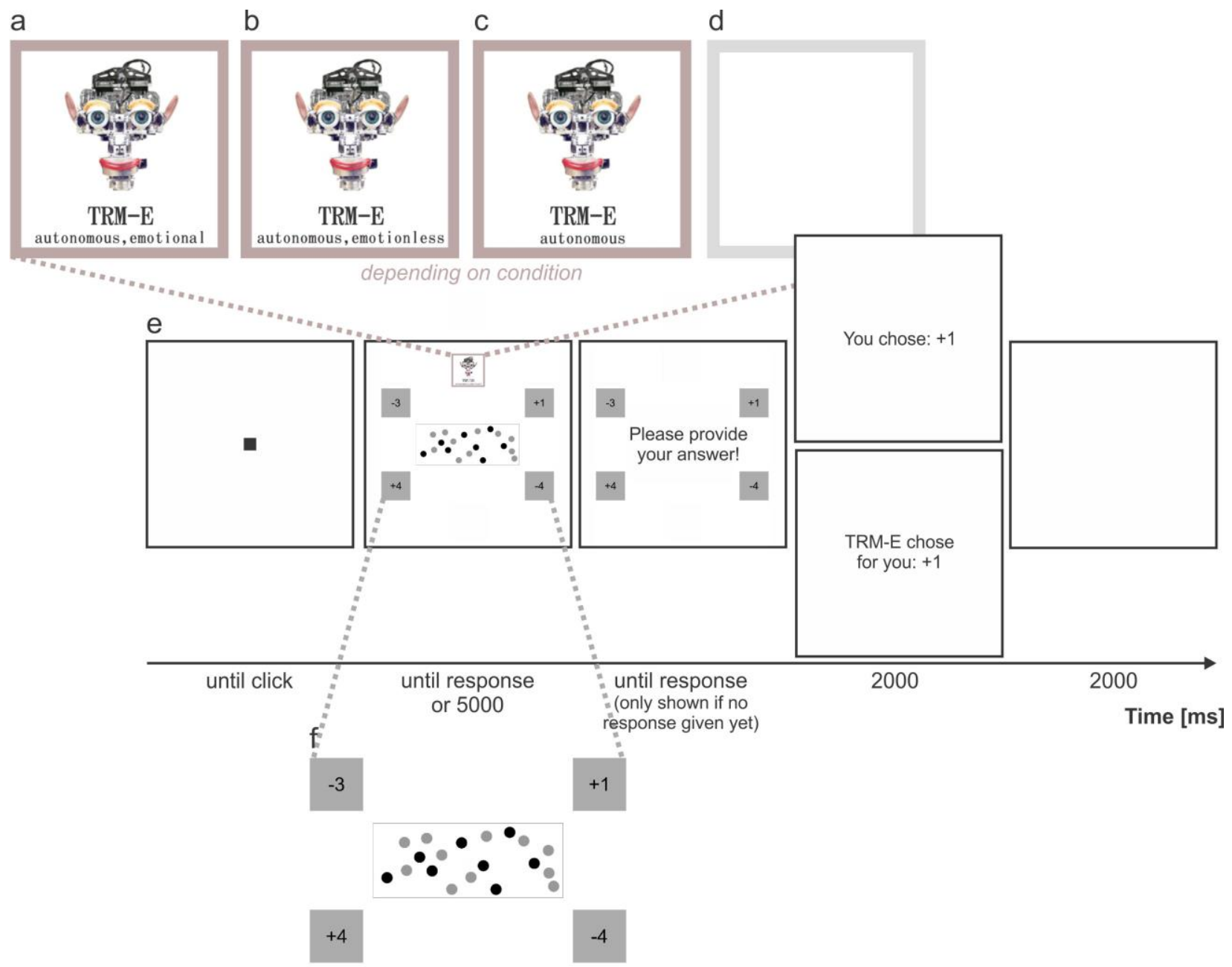

Note. At the beginning of the experiment, each participant was assigned to one of four emotional framing conditions.

Depending on the condition, a different verbal description was shown alongside the robot $(\mathrm{a}, \mathrm{b}, \mathrm{c})$ or no robot and no description was shown at all (d). Each trial started with participants clicking a black rectangle to center the mouse cursor and ended with an empty screen between trials (e). Participants were instructed to count black and gray dots and report the difference score. To do so, participants could use the mouse cursor to select the box with the correct number (f). For example, if there were ten black and nine gray dots, the correct answer box would be "+1". Alternatively, participants could select the robot TRM-E in the experimental conditions depicted in (a), (b), and (c) and let TRM-E answer the question. In the experimental condition depicted in (d), participants cannot rely on TRM-E; no robot and no gray frame were shown during task trials. In (e), answer options and dots are drawn to scale; everything else is not drawn to scale. Sample trials are available at https://youtu.be/kJOoKemAcck. 


\subsection{Design}

Across the two different task types, three main manipulations have been implemented in the present experiment:

1. Possessive determiner with within-participants levels self-referential (i.e., "my") and other-referential (i.e., "its"). This factor is implemented in the affective his-mine-task, refers to the possessive determiner with which the respective nouns are paired, and ultimately affords comparison of self- and other-related (here: robot-related) emotions (Herbert, Herbert, Ethofer, et al., 2011; Weis \& Herbert, 2017).

2. Robot framing with the between-participants levels emotional and autonomous, emotionless and autonomous, autonomous, and control. This factor relates to a manipulation that introduced the robot agent TRM-E (compare Fig. 3: detailed introduction). The following text was presented:

"TRM-E has been solving the brainteaser [TN: the arithmetic problem solving task] for the first time during the winter term 2018 in our laboratory based in [blinded]. TRM-E has been part of our team at [blinded] University for two years. TRM-E was developed by a small startup in the US and will soon be ready for commercial purchase. TRM-E is a very advanced robot. TRM-E can act as independently and autonomously as humans can. TRM-E can also think, plan ahead, and communicate without human supervision. [instruction manipulation]. To detect his surroundings, TRM-E uses two cameras that are installed at the location of the eyes."

Depending on the condition, different instruction manipulations are inserted at the indicated position. For emotional and autonomous "TRM-E has emotional capabilities. TRM-E is capable of detecting and experiencing emotions.", for emotionless and autonomous "TRM-E has no emotional capabilities whatsoever. TRM-E is not capable of detecting and experiencing emotions.", and for autonomous and control "TRM-E can solve complex problems (e.g., crossword puzzles) without supervision." was inserted at the indicated condition. Participants in the emotional and autonomous, emotionless and autonomous, and autonomous conditions were able to select TRM-E during the arithmetic 
problem solving task. Importantly, participants in the control condition were not able to choose TRME and consequentially had to always solve the arithmetic problems on their own. Also note that the labels written next to the robot TRM-E change depending on the condition (see Figure 2a-d)

3. Time with the within-participant levels pre-manipulation and post-manipulation. This factor relates to the time point of the word evaluation task (compare Figure 3) and affords comparing baseline emotions associated with oneself and the robot TRM-E (i.e., pre-manipulation) with emotions associated with oneself and the robot TRM-E after more information had been disclosed about the robotdepending on the cognitive interaction condition - and after the robot has possibly provided support in the arithmetic problem solving task (i.e., post-manipulation).

\subsection{Procedure}

After consenting to participate, participants were introduced to the robot TRM-E without providing in-depth details about the agent ("[...] during the experiment, you will have the chance to receive support from a robot. How this works will be explained later on. At the moment, the only important thing to remember is that the robot is named TRM-E. TRM-E was developed by a small start-up in the US and will soon be ready for commercial purchase.”). Participants then engaged in 64 trials of the affective his-minetask. In half the trials, the noun was paired with the self-referential possessive determiner "my", in the other half with the other-referential possessive determiner "its". Trials were presented in alternating blocks consisting of four trials with the same possessive determiner. The possessive determiner used in the first block was counter-balanced across participants. Before the first and every sixteen trials thereafter, participants were reminded to please associate the other-referential possessive determiner with the robot TRM-E. Participants then were introduced to TRM-E in more detail (see Design: Robot Framing). To ensure that participants did read and remember the main manipulation, participants had to select a corresponding answer out of five answer options. For example, participants needed to select "TRM-E experiences feelings and acts without human supervision") in the emotional and autonomous robot framing condition. If participants selected the wrong answer, they were kindly redirected to the introduction once more and were given another try to select the correct answer. Subsequently, participants were to solve 
arithmetic problems. During the arithmetic problem solving task, a gray box appeared every six trials and reminded participants of their framing condition (e.g., "Remember: TRM-E is an autonomous robot and able to feel or experience emotions."). After completing all trials, participants were to engage in the affective his-mine-task once more, using the same stimuli as in the first iteration. Eventually, participants were to answer demographic questions, manipulation checks (e.g., whether they were relating the words preceded by "its" in the word evaluation task to TRM-E), and exploratory questions (e.g., whether they assume TRM-E to have feelings), and filled out three questionnaires that were included for exploratory purposes (the Inclusion of Other in the Self Scale or Iooiss, Aron et al., 1991; the Toronto Alexithymia Scale 20 or TAS-20, Bagby et al., 1994; and the Patient Health Questionnaire 2 or PHQ-2, Löwe et al., 2005). To be able to explore the impact of the robot framing manipulation on perceived competence, participants also had to rate how proficient they perceived themselves as well as the robot TRM-E on a visual analogue scale ranging from "very unproficient" to "very proficient", both immediately after the robot framing manipulation (i.e., the detailed introduction of TRM-E), and at the end of the study in the survey section.

\section{Figure 3}

Procedure

\begin{tabular}{|c|c|c|c|c|c|c|c|}
\hline $3 \mathrm{~min}$ & $2 \min$ & $6 \mathrm{~min}$ & $4 \mathrm{~min}$ & $7 \mathrm{~min}$ & $6 \mathrm{~min}$ & $7 \mathrm{~min}$ & // $35 \mathrm{~min}$ \\
\hline \multirow[t]{2}{*}{$\begin{array}{l}\text { Consent form, } \\
\text { welcome } \\
\text { message }\end{array}$} & $\begin{array}{l}\text { Brief } \\
\text { introduction of } \\
\text { robot TRM-E }\end{array}$ & $\begin{array}{c}\text { Affective his- } \\
\text { mine-task, } \\
\text { pre- } \\
\text { manipulation }\end{array}$ & $\begin{array}{l}\text { Detailed } \\
\text { introduction of } \\
\text { robot TRM-E }\end{array}$ & $\begin{array}{l}\text { Arithmetic } \\
\text { problem } \\
\text { solving task }\end{array}$ & $\begin{array}{c}\text { Affective his- } \\
\text { mine-task, } \\
\text { post- } \\
\text { manipulation }\end{array}$ & Surveys & \\
\hline & $\begin{array}{l}\text { (same for all } \\
\text { participants) }\end{array}$ & & $\begin{array}{c}\text { (depending on } \\
\text { group) }\end{array}$ & & & & \\
\hline
\end{tabular}

\subsection{Analyses}

All analyses were made using R (R Core Team, 2013) and its car (Fox \& Weisberg, 2018) package and tidyverse (Wickham et al., 2019) package set. Here, the preregistered omnibus ANOVAs are described. Post-hoc analyses will be described in the Results section. 


\subsubsection{Data Cleaning}

Data quality necessitated cleaning of data beyond what was described in the preregistration procedure. In a first step, trials of the affective his-mine-task with reaction times (RTs) below $200 \mathrm{~ms}$ (5.4\% of trials) or above $5000 \mathrm{~ms}$ (3.5\% of trials) were excluded from analysis. In a second step, trials that deviated more than three standard deviations from the individual mean were excluded $(1.5 \%$ of remaining trials). Because of bad signal to noise ratio, participants for which less than 8 out of 32 trials remained for any of the four Possessive Determiner x Time cells were excluded from analyses (9 participants).

\subsubsection{H1-1: Self-Positivity Bias can be Replicated (RT)}

To analyze whether the RT-related self-positivity bias shown in previous research (Watson et al., 2007; Weis \& Herbert, 2017) can be replicated in the current study, a 4 (robot framing) x 2 (possessive determiner) mixed ANOVA with the pre-manipulation RT in the affective his-mine task was employed. A main effect of possessive determiner with faster reactions for self-referential in comparison to otherreferential would confirm the hypothesis.

\subsubsection{H1-2: Self-Positivity Bias can be Replicated (Valence)}

Similar to the procedure for H1-1, a 4 (robot framing) x 2 (possessive determiner) mixed ANOVA with the pre-manipulation valence indicated as indicated by the ratings in the affective his-mine task was employed to analyze whether the valence-related self-positivity-bias can be replicated. A main effect of possessive determiner with higher valence for self-referential in comparison to other-referential would confirm the hypothesis.

\subsubsection{H2-1: Robot Framing Impacts Emotional Processing (RT)}

To analyze whether cognitively interacting with the differentially introduced versions of TRM-E impacts the emotional processing of self- and other-related information, a 4 (robot framing) x 2 (possessive determiner) $\mathrm{x} 2$ (Time) mixed ANOVA with RT in the affective his-mine task as dependent variable was employed. 


\subsubsection{H2-2: Robot Framing Impacts Emotional Processing (Valence)}

Similar to the procedure for H2-1, to analyze whether cognitively interacting with the differentially introduced versions of TRM-E impacts the emotional processing of self- and other-related information in terms of valence, a 4 (robot framing) x 2 (possessive determiner) x 2 (time) mixed ANOVA with valence ratings in the affective his-mine task as dependent variable was employed.

\section{Results}

\subsection{H1-1: Self-positivity Bias can be Replicated (RT)}

In line with H1-1, reactions were faster for self-referential $(M=1059 \mathrm{~ms})$ than for other-referential $(M=1149 \mathrm{~ms})$ possessive determiners $\left(F(1,227)=39.9, p<.0001, \eta_{\mathrm{G}}{ }^{2}=.01\right)$; compare Figure $4 \mathrm{a}$. The interaction between robot framing and possessive determiner $\left(F(3,227)=1.2, p=.3272, \eta_{\mathrm{G}}{ }^{2}<.01\right)$ as

well as the main effect of robot framing $\left(F(3,227)=0.5, p=.6964, \eta_{\mathrm{G}}{ }^{2}<.01\right)$ did not reach the .05 significance level. Our participants thus processed self-related positive emotional information quicker than TRM-E-related positive emotional information. The confirmation of H1-1 extends previous findings in which participants processed self-related positive emotional information quicker than positive emotional information related to other humans (Weis \& Herbert, 2017) and suggests that RT is a valid measure for differentiating between self-concept and concepts of other agents.

\subsection{H1-2: Self-positivity Bias can be Replicated (valence)}

In line with H1-2, valence ratings were higher for self-referential $(M=.729)$ than for otherreferential $(M=.433)$ possessive determiners $\left(F(1,227)=72.9, p<.0001, \eta_{\mathrm{G}}{ }^{2}=.14\right)$; compare Figure $4 \mathrm{~b}$. The interaction between emotional framing and possessive determiner $\left(F(3,227)=1.0, p=.3756, \eta_{\mathrm{G}}^{2}<\right.$ $.01)$ as well as the main effect of emotional framing $\left(\left(F(3,227)=.9, p=.4644, \eta_{\mathrm{G}}{ }^{2}<.01\right)\right.$ did not reach the .05 significance level. Our participants thus evaluated self-related positive emotional information more positively than TRM-E-related positive emotional information. Analogously to the conformation of H1-1, the confirmation of H1-2 extends previous findings in which participants evaluated self-related positive 
emotional information more positively than positive emotional information related to other humans (Weis \& Herbert, 2017) and suggests that valence is a valid measure for differentiating between self-concept and concepts of other humans and robots. More specifically, the substantially larger effect size of the valence in comparison to the RT measure of the self-positivity bias suggests that the former might be a more direct and less disturbed measure.

\section{Figure 4}

Affective His-Mine-Task: Pre-Manipulation RT and Valence

a

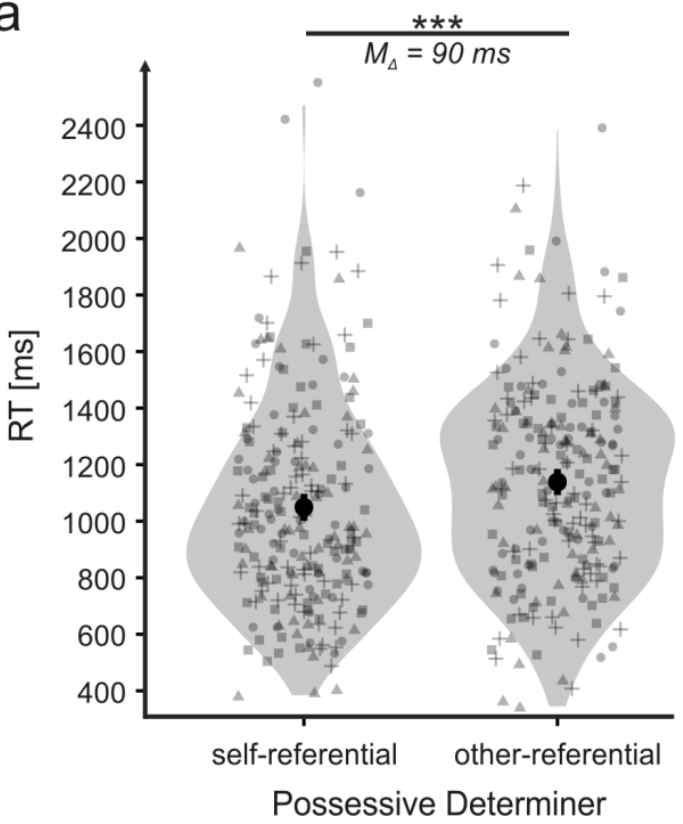

b

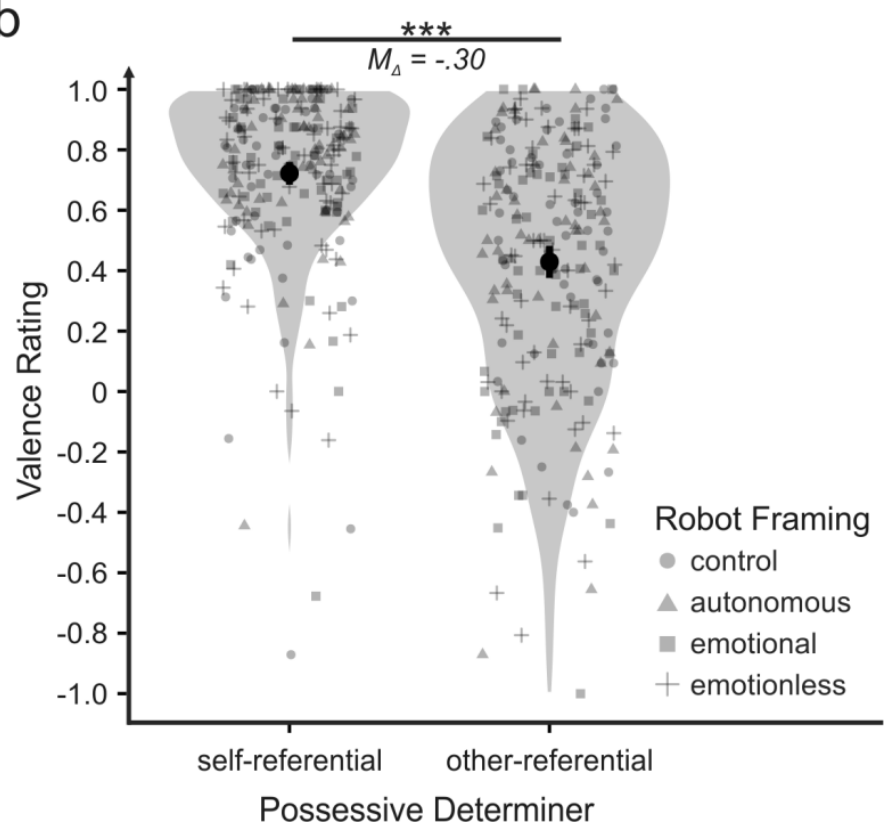

Note: RT (a) and valence ratings (b) in the pre-manipulation time window. Black dots indicate grand averages. Gray dots indicate individual averages. Error bars indicate $95 \%$ CI. $* * *: p<.0001$

\subsection{H2-1: Robot Framing Impacts Emotional Processing (RT)}

Contrary to $\mathbf{H 2 - 1}$, robot framing, possessive determiner, and time did not interact in their influence on $\operatorname{RT}\left(F(3,227)=1.9, p=.1326, \eta_{\mathrm{G}}^{2}<.01\right)^{5} ;$ compare Figure 5. The interactions between robot framing

\footnotetext{
${ }^{5}$ We conducted an analogue ANOVA in which RT values were standardized within participants to render
} participants with large standard deviations and large RT differences from pre-manipulation to post-manipulation 
and possessive determiner $\left(F(3,227)=.9, p=.4220, \eta_{\mathrm{G}}{ }^{2}<.01\right)$ as well as robot framing and time $(F(3$, $\left.227)<.1, p=.9956, \eta_{\mathrm{G}}{ }^{2}<.01\right)$, did also not reach the .05 significance level. The interaction between time and possessive determiner did reach significance $\left.\left(F(1,227)=8.4, p=.0041, \eta_{\mathrm{G}}{ }^{2}<.01\right)\right)$. Robot framing alone had no impact on $\operatorname{RT}\left(F(3,227)=.5, p=.6591, \eta_{\mathrm{G}}{ }^{2}=.01\right)$. The main effects of possessive determiner $\left.F(1,227)=32.7, p<.0001, \eta_{\mathrm{G}}{ }^{2}=.01\right)$, and time $\left.F(1,227)=38.5, p<.0001, \eta_{\mathrm{G}}{ }^{2}=.02\right)$ are not further discussed due to the significant two-way interaction.

To further explore the significant two-way interaction, we conducted a dependent $t$-test comparing self-referential and other-referential RT differences $\left(t(1,230)=2.9, p=0.0043, M_{\Delta}=43 \mathrm{~ms}\right.$; Figure 5). Thus, participants speeded up the processing of TRM-E-related more than the processing of self-related positive information from pre- to post-manipulation. We interpret this finding as the consequence of increased familiarity with TRM-E from pre- to post-manipulation. However, we consequentially would expect that the control robot framing condition should exhibit no such differential increase in familiarity (i.e., differential decrease in RT), a proposition that is met descriptively (compare Figure 5: otherreferential) but cannot be confirmed using the present statistical procedures given the insignificant threeway interaction. The familiarity interpretation would also align with a simple linear regression analysis predicting other-referential RT change from pre- to post-manipulation based on pre-manipulation otherreferential RT $\left(F(1,229)=12.3, p<.001 ; R_{\text {Adjusted }}^{2}=.05\right)$. A one-second-increase in pre-manipulation RT led to a 165-millisecond-decrease in pre-post RT change. Thus, the participants who took the longest for evaluating robot-related emotions in the pre-manipulation time window were the ones who speeded up their evaluation the most in the post-manipulation time window.

more comparable to participants with lower deviations and thus lower RT differences. Results were highly comparable to the reported analysis with raw RT values which is why we decided to only report unstandardized results. 


\section{Figure 5}

\section{Affective His-Mine-Task: RT Changes From Pre-to Post-Manipulation}

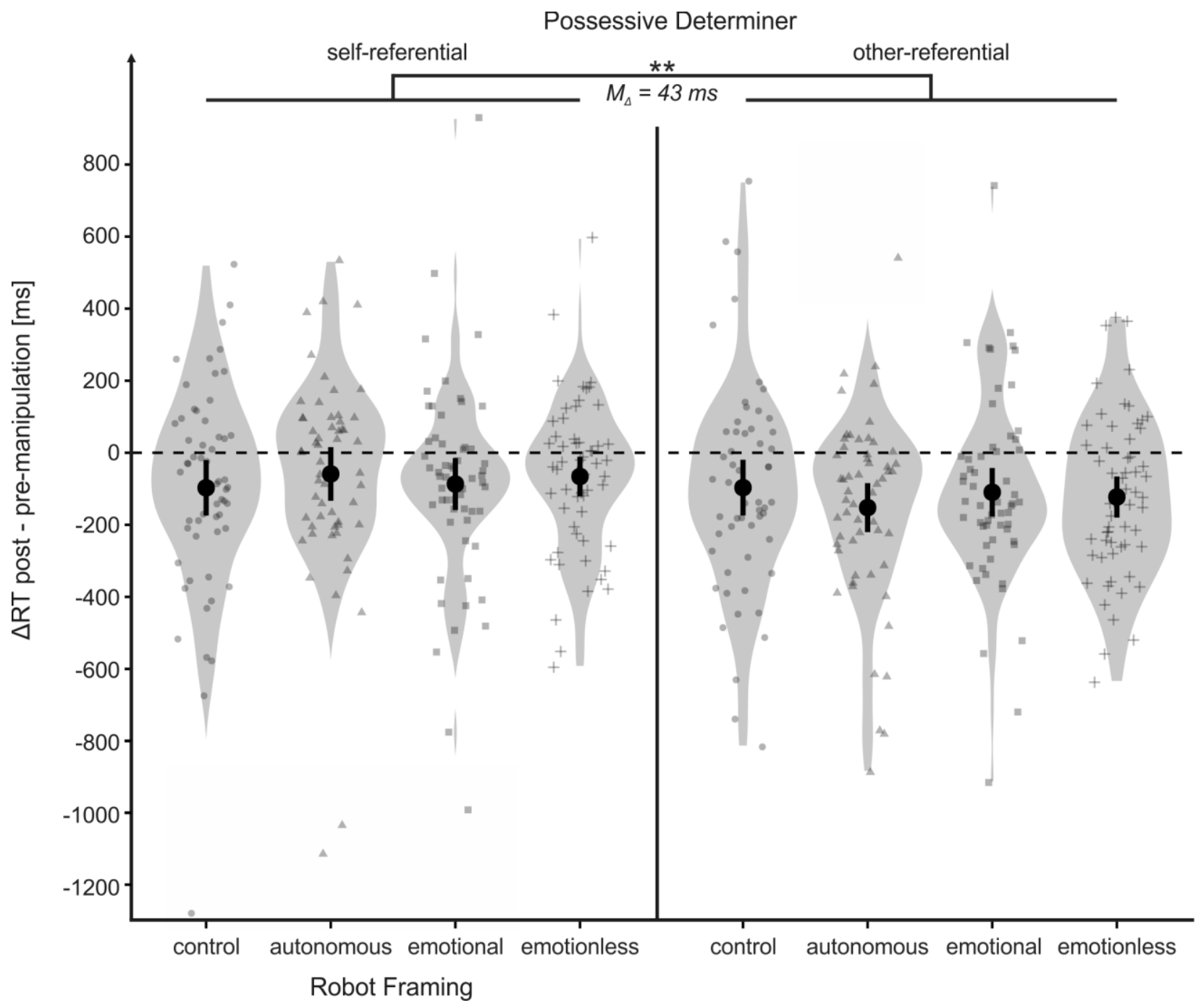

Note. When compared to the pre-manipulation baseline (see Figure 3), target words paired with other-referential possessive determiners are evaluated quicker post-manipulation than words paired with self-referential possessive determiners. Error bars indicate $95 \%$ CI. "emotional" refers to the emotional and autonomous, "emotionless" to the "emotionless and autonomous" robot framing condition. ${ }^{* *}: p=.0043$ 


\subsection{H2-2: Robot Framing Impacts Emotional Processing (Valence)}

In line with H2-2, robot framing, possessive determiner, and time interacted in their influence on valence ratings $\left(F(3,227)=3.0, p=.0324, \eta_{\mathrm{G}}{ }^{2}<.01\right)$; compare Figure 6. Similarly, the interactions between possessive determiner and time $\left(F(1,227)=8.2, p=.0045, \eta_{\mathrm{G}}{ }^{2}<.01\right)$ as well as robot framing and time $\left(F(3,227)=3.1, p=.0260, \eta_{\mathrm{G}}^{2}<.01\right)$ reached the .05 significance level. The interaction between robot framing and possessive determiner did not reach significance $\left.\left(F(3,227)=.2, p=.9260, \eta_{\mathrm{G}}{ }^{2}<.01\right)\right)$. Robot framing $\left(F(3,227)=.7, p=.5278, \eta_{\mathrm{G}}{ }^{2}<.01\right)$ as well as time $\left(F(1,227)=.2, p=.6521, \eta_{\mathrm{G}}{ }^{2}=.01\right)$ on its own had no influence on valence ratings. The main effect of possessive determiner $F(1,227)=63.9$, $\left.p<.0001, \eta_{\mathrm{G}}{ }^{2}=.10\right)$ as well as the significant two-way interactions are not further discussed due to the significant three-way interaction.

To further explore the three-way interaction, eight dependent $t$-tests were conducted to delineate the conditions (Robot Framing x Possessive Determiner) in which participants exhibited changes in valence ratings from pre- to post-manipulation. Note that the dependent $t$-tests are equivalent to one-sample $t$-tests that test the difference between pre- and post-manipulation ratings to $\mu=0$, see Figure 6 . Ratings from pre- to post-manipulation did change for the autonomous and emotionless robot framing when rating target words with the self-referential possessive determiner $(M=-.08, t(58)=2.4, p=.0207, d=-.31)$, and for the autonomous and the emotional and autonomous robot framing conditions when rating target words with the other-referential possessive determiner (autonomous: $M=.10, t(55)=2.2, p=.0293, d=$ .30 ; emotional and autonomous: $M=.15, t(58)=2.6, p=.0111, d=.34)$. All other $t$-tests suggested no differences (all $t<1.7$, all $p>.1$ ).

These findings suggest that interacting with robots can have consequences for both the emotional self-concept as well as the emotional concept of the robot. On the one hand, introducing the robot as autonomous or autonomous and emotionally capable and subsequently solving a task together led to more positive evaluations of robot-related words. On the other hand, introducing the robot as autonomous and emotionally incapable led to more negative evaluations of self-related words. That being said, one should keep in mind that the corresponding effect sizes $\left(\eta_{\mathrm{G}}{ }^{2}<.01\right.$ and $d \sim 0.3$ ) can be considered small (e.g., Co- 
hen, 1988; Lakens, 2013). The small effect size might reflect both the existence of various other determinants of state self- and other-concepts (cf. Heatherton \& Polivy, 1991) as well as noise induced by a relatively small number of aHMP trials.

\section{Figure 6}

Affective His-Mine-Task: Valence Changes From Pre- to Post-Manipulation

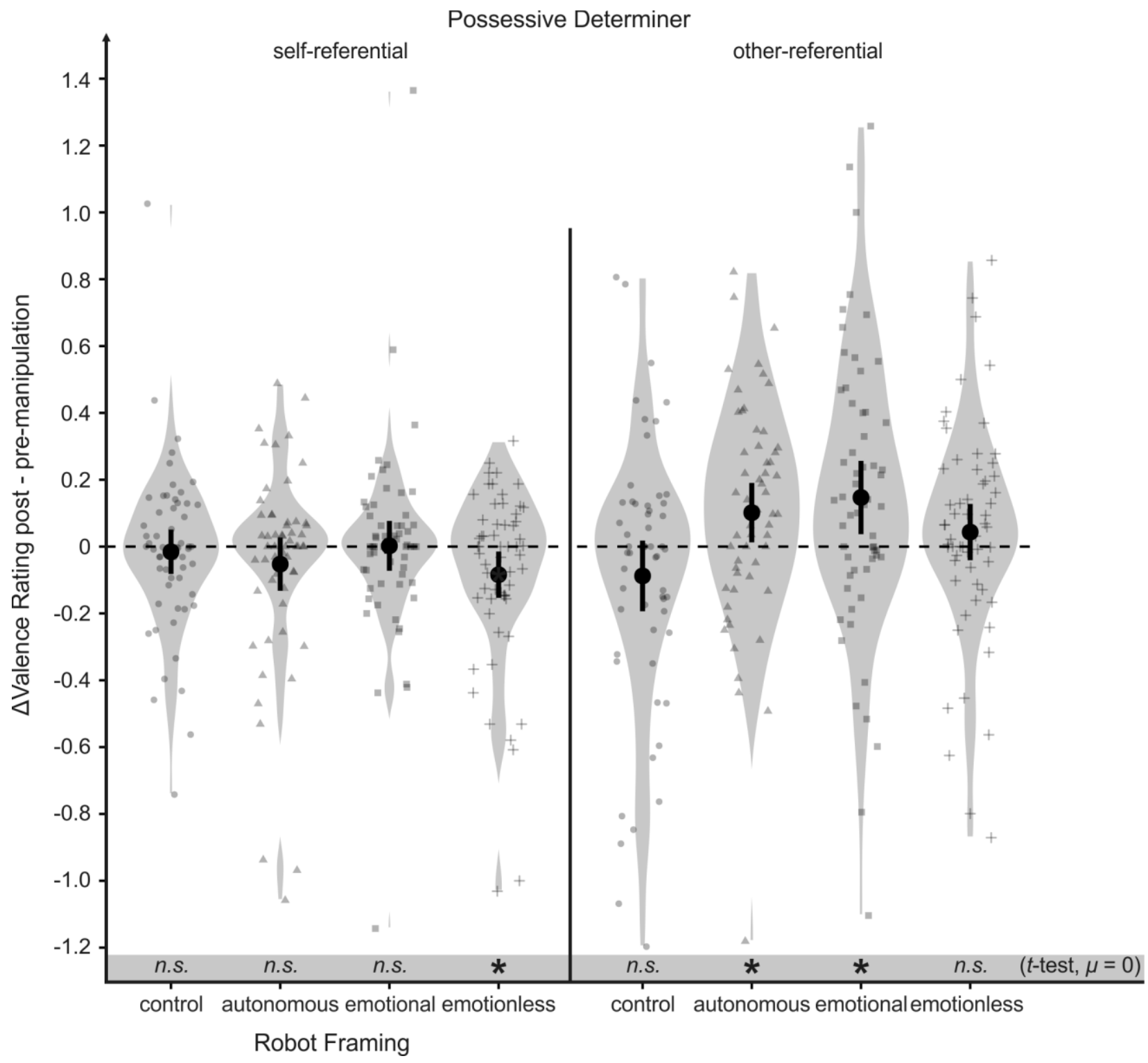

Note. Error bars indicate $95 \%$ CI. "emotional" refers to the emotional and autonomous, "emotionless" to the emotionless and autonomous robot framing condition. $*: \mathrm{p}<.03$, n.s.: $\mathrm{p}>.10$ 


\subsection{Exploratory Analyses: Proficiency Ratings}

Robot framing, rating target (self or TRM-E), and time interacted in their influence on proficiency ratings $\left(F(3,227)=2.71, p=.0458, \eta_{\mathrm{G}}^{2}<.01\right)$; compare Figure S1. Similarly, the interaction between rating Target and time $\left(F(1,227)=18.5, p=.0001, \eta_{\mathrm{G}}{ }^{2}=.01\right)$ reached the .05 significance level. The interactions between robot framing and rating target $\left.\left.F(3,227)=1.3, p=.2918, \eta_{\mathrm{G}}{ }^{2}=.01\right)\right)$ and robot framing and time $\left.F(3,227)=1.3, p=.2852, \eta_{\mathrm{G}}^{2}<.01\right)$ did not reach significance. Robot framing $(F(3,227)=$ $\left.1.6, p=.1797, \eta_{\mathrm{G}}{ }^{2}=.01\right)$ as well as time $\left(F(1,227)=.7, p=.4174, \eta_{\mathrm{G}}{ }^{2}<.01\right)$ on their own had no influence on valence ratings. The main effect of rating target $\left(F(1,227)=98.5, p<.0001, \eta_{\mathrm{G}}{ }^{2}=.14\right)$ as well as the significant two-way interactions are not further discussed due to the significant three-way interaction.

One-way ANOVAs and $t$-tests were used to explore this effect further. During pre-manipulation time, participants in all robot framing conditions rated both own $\left(F(3,227)=.7, p=.5283, \eta_{\mathrm{G}}{ }^{2}<.01\right)$ as well as TRM-E's $\left(F(3,227)=1.3, p=.2823, \eta_{\mathrm{G}}{ }^{2}=.02\right)$ proficiency similarly (though TRM-E's proficiency was rated higher; $\left.M_{\Delta}=25.3, t(230)=11.0, p<.0001\right)$. We therefore focused on the proficiency rating changes from pre- to post-manipulation using eight (Robot Framing x Rating Target) dependent $t$-tests; compare Figure S1. Results indicated that only participants in the control robot framing condition exhibited rating changes from pre- to post-manipulation both regarding self-related $\left(M_{\Delta}=5.6, t(56)=2.1, p=\right.$ $.0417)$ as well as TRM-E's $\left(M_{\Delta}=-12.7, t(56)=3.4, p=.0012\right)$ proficiency ratings. There was a trend towards an increase regarding own proficiency ratings for the emotionless robot framing condition $\left(M_{\Delta}=\right.$ 5.8, $t(58)=1.9, p=.0580)$. All other changes were statistically insignificant (all $t\langle 1.5$, all $p\rangle .14$, all $\left.\left|M_{\Delta}\right|<4.5\right)$

The decreased TRM-E proficiency estimates for the control condition indicate that the estimates are linked to an actual interaction. The increased self-related proficiency estimates for the control robot framing condition in turn suggests that participants are sensitive to how frequently they solved the task on their own. This in turn also suggests that participants in the other robot framing conditions did not misattribute TRM-E's proficiency as their own proficiency. This is contrasting other findings that suggest that outsourcing cognitive processing to technology can lead to upwardly biased perception of task- 
specific own cognitive abilities (at least in the trivia knowledge domain: Fisher et al., 2015; Hamilton \& Yao, 2018; Pieschl, 2019).

\subsection{Exploratory Analyses: Arithmetic Task Performance}

To get a crude estimate of the arithmetic task's difficulty, we analyzed data for participants that had to solve the tasks on their own, i.e. for participants in the control robot framing condition. A one-sample $t$ test confirmed that the task was difficult but participants performed above the chance level $\mu=.25(M=$ $.47, t(56)=7.7, p<.0001)$. Mean accuracy of all trials in which participants chose to answer the arithmetic task on their own in the remaining robot framing conditions was comparable $(M=.46)$. In general, a pre-manipulation self-positivity bias both in terms of RT $\left(r_{\text {Pearson }}=.19, t(184)=2.7, p=.008\right)$ and valence $\left(r_{\text {Pearson }}=.16, t(184)=2.7, p=.03\right)$ was mildly positively associated with arithmetic task accuracy. Participants who answered on their own in less than $25 \%$ of trials were omitted for these correlations because of their noisy accuracy estimates.

\subsection{Exploratory Analyses: Cognitive Offloading}

In the conditions in which participants were able to choose between answering on their own and getting support from TRM-E (i.e., all robot framing conditions except for the control condition), participants chose to offload the arithmetic task in 13.7 out of 36 or $38 \%$ of all trials to the robot TRM-E. No

differences between the three conditions existed $\left(F(2,171)=1.6, p=.2046, \eta_{\mathrm{G}}{ }^{2}=.02\right)$. This exploratory finding indicates that differential emotional consequences can exist even when overt interaction behavior remains comparable.

\subsection{Exploratory Analyses: PHQ-2}

People are more likely to associate positive than negative events with themselves (self-serving attributional bias or self-positivity bias; Mezulis et al., 2004). For samples with depression however, this bias was found to be substantially reduced (Mezulis et al., 2004). To co-validate this finding and the use of the present paradigm, we correlated the PHQ-2 score (ranging from 0 to 6) with the self-positivity bias as 
indicated by RT (i.e., RT when evaluating target words with other-referential minus RT when evaluating target words self-referential possessive determiner; see H1-1) as well as valence (i.e., valence when evaluating target words with self-referential minus valence when evaluating target words other-referential possessive determiner; see H1-2). In line with the findings reported by Mezulis and colleagues (2004), both the RT-based $\left(t(229)=3.4, p=.0007, r_{\text {Pearson }}=-.22\right)$ as well as the valence-based $(t(229)=2.1, p=$ $\left..0393, r_{\text {Pearson }}=-.14\right)$ self-positivity bias decreased with increasing PHQ-2 score $\left(M_{\mathrm{PHQ}-2}=1.86\right.$; range from 0 to 6). These findings further strengthen the validity of the present paradigm for measuring the emotional self-concept.

\subsection{Exploratory Analyses: TAS-20}

Following the same rationale, the self-positivity bias should be reduced if one has little access to one's own emotions. To confirm this exploratory hypothesis, we correlated TAS-20 scores with the selfpositivity bias as indicated by RT and valence (identical procedure as in Exploratory Analyses: PHQ-2). In line with our expectations, both RT-based $\left(t(229)=4.0, p<.0001, r_{\text {Pearson }}=-.25\right)$ as well as valencebased $\left(t(229)=2.9, p=.0047, r_{\text {Pearson }}=-.19\right)$ self-positivity bias decreased with increasing TAS-20 score $\left(M_{\mathrm{TAS}-20}=50.71\right.$; range from 21 to 79$)$. These findings further strengthen the validity of the present paradigm for measuring the emotional self-concept.

\subsection{Exploratory Analyses: Iooiss}

Building on our initial expectations (compare $\mathrm{H} 2$ ) we were especially interested in whether the changes in RT and valence from pre- to post-manipulation when evaluating target words with otherreferential possessive determiner (compare right sides of Figures 5 and 6) would be possibly correlated with the inclusion of TRM-E into the self. Correlation analyses for both RT $\left(t(229)=.7, p=.5066, r_{\text {Pearson }}\right.$ $=.04)$ and valence $\left(t(229)=.4, p=.6753, r_{\text {Pearson }}=.03\right)$ changes with the Iooiss scores provided no support for this idea. 


\subsection{Exploratory Analyses: What is the Origin of the Valence Rating Changes?}

To further investigate the origin of the significant valence rating changes from pre- to postmanipulation (compare Figure 6), we conducted multiple linear regression analyses with several predictors we deemed relevant for how robot framing could impact self- and robot-concept. We used premanipulation valence ratings to account for the baseline, the TAS-20 score, the Iooiss score, and the change of robot-related proficiency ratings from pre- to post-manipulation to predict the changes in valence ratings in the respective robot framing condition.

\section{Self-referential Possessive Determiner, Emotionless Robot Framing}

The regression equation was trending $\left(F(4,54)=2.1, p=.095 ; R_{\text {Adjusted }}^{2}=.07\right)$. Valence changes were equal to $0.190-.336 *$ pre-manipulation valence $-.002 *$ robot-proficiency rating change $-.002 *$ TAS-20 score $+.011 *$ Iooiss score. Pre-manipulation valence was a significant $(t=2.6, p=.011, V I F=$ 1.1) predictor. Robot-proficiency rating change $(t=1.5, p=.146, V I F=1.0)$, TAS-20 $\operatorname{score}^{6}(t=.6, p=$ $.534, V I F=1.4)$, and Iooiss score $(t=.5, p=.593, V I F=1.4)$ were statistically insignificant predictors. The analysis provides no conclusive insight into the mechanism behind the decreased self-positivity bias. One might want to consider higher perceived robot proficiency (here: $p=.146$ ) as potential predictor of a lower self-positivity bias in future investigations.

\section{Other-referential Possessive Determiner, Autonomous Robot Framing}

The regression equation was significant $\left(F(4,51)=4.8, p=.002 ; R_{\text {Adjusted }}^{2}=.21\right)$. Valence changes were equal to $0.209-.381 *$ pre-manipulation valence $+.004 *$ robot-proficiency rating change $+.0001 *$ TAS-20 score $+.017 *$ Iooiss score. Pre-manipulation valence was a significant $(t=3.8, p=.0004$, VIF $=$

${ }^{6}$ For the interested reader, we want to add that the Externally Oriented Thinking subscale of the TAS-20 was the only significant predictor $(t=3.5, p=.001, V I F=1.5$, weight $=-.03)$ beyond pre-manipulation valence when TAS-20 score was subdivided into its three subscales as predictors. When using subscales, the regression equation was significant $\left(F(6,54)=3.8, p=.003 ; R_{\text {Adjusted }}^{2}=.23\right)$. We decided to omit reporting subscale analyses on other occasions for statistical and simplicity reasons. 
1.1) and robot-proficiency rating change a trending $(t=1.9, p=.063, V I F=1.0)$ predictor. Neither TAS20 score $(t<.1, p=.964, V I F=1.2)$ nor Iooiss score $(t=.7, p=.482, V I F=1.4)$ were significant predictors. The analysis provides first evidence for an impact of perceived robot proficiency for the positivity of the robot concept. A 10-point increase in perceived proficiency (max. value: 100) was associated with a .04-point increase in valence (max. value: 1), when holding all other predictors constant.

\section{Other-referential Possessive Determiner, Emotional Robot}

The regression equation was significant $\left(F(4,54)=7.8, p<.0001 ; R_{\text {Adjusted }}^{2}=.32\right)$. Valence changes were equal to $0.453-.578 *$ pre-manipulation valence $+.005 *$ robot-proficiency rating change $-.006 *$ TAS-20 score $+.05 *$ Iooiss score. Pre-manipulation valence $(t=4.8, p<.0001$, VIF $=1.2)$ and Iooiss score $(t=2.0, p=.047, V I F=1.2)$ were significant and robot-proficiency rating change $(t=1.8, p=.074$, $V I F=1.0)$ and TAS-20 scores $(t=1.9, p=.065, V I F=1.1)$ trending predictors. The analysis provides additional evidence for the importance of the framing of a robot collaborator. While the positive robot concept was exclusively tied to perceived proficiency in the autonomous framing condition, it seems to be additionally tied to an individual's emotional processing as indicated by the TAS-20 and the Iooiss scores in the emotional framing condition. Note that the effects of both TAS-20 and Iooiss are questionable from a statistical point of view. However, also note that the effects are in the expected direction and are only present in the expected, i.e. the emotional, robot framing condition.

\subsection{Exploratory Analyses: Remarks about TAS-20 and Evaluation of Robot Feelings}

When exploring the data further, surprisingly, higher TAS-20 scores were consistently correlated with whether - at the very end of the study — participants believed the robot to have feelings ("The robot TRM-E does have feelings"; 1: "strongly disagree", 2: "disagree", 3: "agree", 4: "strongly agree"). Higher TAS-20 scores were associated with higher belief ratings for the autonomous $(t(54)=3.8, r=.46, p=$ $.005)$, control $(t(55)=2.6, r=.33, p=.012)$, and emotionless $(t(57)=5.8, r=.61, p<.0001)$, but not the emotional $(t(57)=1.0, r=.14, p=.300)$ emotional framing conditions; Figure 7 . We decided to report these highly explorative findings because they were stable across independent samples and- 
counterintuitively, at least for the authors - suggest that alexithymic individuals' default mode is to ascribe feelings to robots rather than the other way around. Individuals with low TAS-20 scores only ascribed feelings to the robot in the emotional framing condition, resulting in the insignificant correlation for that condition.

\section{Figure 7}

\section{Relationship between TAS-20 Score and Beliefs Regarding Robot Feelings}
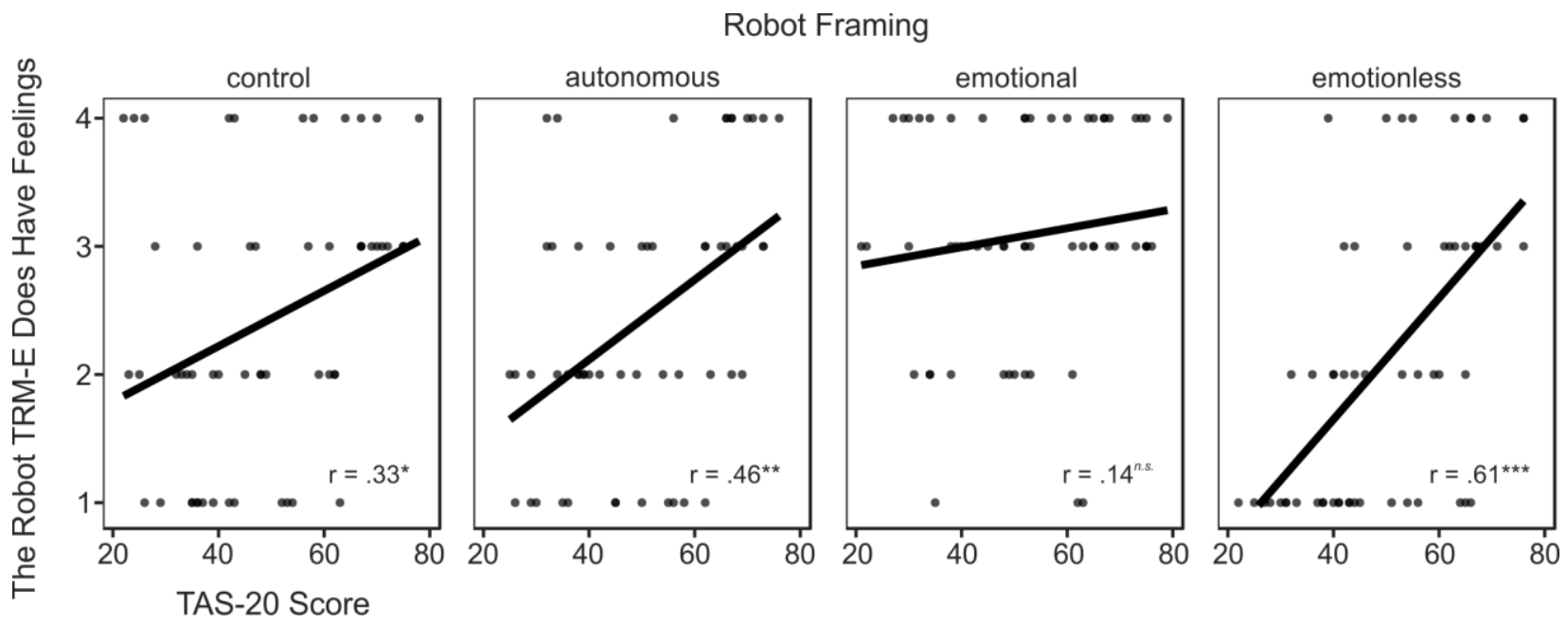

Note. "emotional" refers to the "emotional and autonomous", "emotionless" to the "emotionless and autonomous" robot framing condition. 1: "strongly disagree", 2: "disagree", 3: "agree", 4: "strongly agree"; *** : $p<.0001, * *: p$ $=.005, *: p=.012$, n.s. $: p=.300$

\subsection{Exploratory Analyses: Age}

Earlier research indicated that for adult samples, increasing age is associated with increasing selfpositivity (Mezulis et al., 2004). This association can be confirmed using the pre-manipulation RT ( $t(228)$ $\left.=4.2, r_{\text {Pearson }}=.27, p<.0001\right)$ and pre-manipulation valence $\left(t(228)=2.7, r_{\text {Pearson }}=-.17, p=.0082\right)$ data. To explore whether this heightened age-related self-positivity baseline might protect against the decrease in self-positivity observed after interacting with an emotionless robot, we correlated the difference between self-related pre- and post-manipulation valence in the emotional robot framing condition with age. The results do not suggest a protective function of age $\left(t(56)=0.33, r_{\text {Pearson }}=.04, p=.7436\right)$. 


\section{Discussion}

Do beliefs about the emotional capabilities of robot collaborators impact emotional self- and otherconcepts during human-robot interaction? Here, we first validated the suitability of the aHMP for measuring emotional self- and other concepts in a human-robot rather than the standard human-human interaction context. We then used an interactive paradigm to show that (1) framing a telepresent robot collaborator as emotionless can have negative consequences for the emotional self-concept and that framing a telepresent robot collaborator as (2) autonomous or (3) emotional can have positive consequences for the emotional robot-concept. The origins of (1) remained largely speculative after additional exploratory analyses. Preliminary evidence suggests (2) and (3) to be associated with perceived robot proficiency and (3) to be additionally associated with a continuous alexithymia measure and by how much the robot was included into the self. Lastly and unexpectedly, we found participants who scored high in an alexithymia measure to be substantially more rather than less likely to ascribe feelings to the robot interaction partner. In sum, we presented evidence for specific emotional consequences of interacting with telepresent robots that should be kept in mind when designing HRI contexts.

\subsection{Emotional Self-Concept}

Positive self-concepts have previously been associated with mental well-being (Mezulis et al., 2004; Taylor \& Brown, 1988, 1994; Winter et al., 2015) and increased cognitive performance (Spencer et al., 1999). Here, both associations were confirmed. A more positive emotional self-concept at premanipulation baseline as indicated by the his-mine task was associated with lower depression screening scores and higher arithmetic task performance. After collaborating with an "emotionless" robot, the positive self-concept across all participants ${ }^{7}$ in that condition decreased by more than $10 \%$ (from .73 to .65 out of 1). Given the modest belief manipulation and the rather superficial interaction with the telepresent robot when compared to real-world contexts with copresent robots $(\mathrm{Li}, 2015)$, we argue an effect of this size to

\footnotetext{
${ }^{7}$ Participants with higher depression screening scores exhibited no larger decrease than participants with
} lower scores $\left(t(57)=0.3, p=.7655, r_{\text {Pearson }}=.04\right)$. 
be substantial, and — given the associations with mental health and performance-also to be relevant. To us, it is intriguing to see that even rather superficial online collaborations with telepresent robots seem to constitute social settings that seem to have the potential to cause psychological harm. Similar negative consequences for human interaction partners' self-esteem have been shown after a physically copresent human-sized robot informed the humans that it would not like to see them again (Nash et al., 2018).

What leads to this decrease? Our current data unfortunately provides little guidance here, only very mildly suggesting that higher perceived robot proficiency might play a role. We therefore can only engage in a thought experiment: What if participants perceived the need to receive help for the rather difficult arithmetic task but had to pay emotional costs when accepting help from an emotionless and thus rather anti-social $^{8}$ entity? Participants might have "hated themselves" for accepting the help. Seeking help can threaten self-esteem and thus affect the emotional self-concept (e.g., Tessler \& Schwartz, 1972; Schroeder et al., 2015), and seeking help from an emotionless entity might have enhanced the threat due to a less benevolent, less supportive and instead anti-social setting. It is clear that further investigations are necessary to elucidate the underpinnings of the decrease.

\subsection{Emotional Robot-Concept}

Being in a romantic relationship renders our emotional concept of our partner more positive (Meixner \& Herbert, 2018). Here, we provide first evidence for similar emotional processes when collaborating with robots. Specifically, the emotional concept of a telepresent robot collaborator got more positive after if that robot was introduced as either autonomous or autonomous and able to experience emotions. Importantly, the emotional concept was not adjusted when no collaboration took place or the robot was introduced as autonomous but incapable of experiencing emotions.

${ }^{8}$ People do establish and use mental models about robot interaction partners (Weis \& Wiese, 2020). Specifically, describing a telepresent robot as emotionless leads to less cooperation in social but not analytical tasks (Wiese et al., 2021). 
Why would a more positive emotional robot-concept be relevant? It is known that the emotional other-concept is relevant for how we interact with fellow humans (Bartholomew \& Horowitz, 1991; Bowlby, 1979) and preliminary findings suggest that the same should hold when interacting with robots (Dziergwa et al., 2018). The exact manner of how the robot-concept would influence the interaction style cannot be inferred from the present data. However, previous studies indicate that negative other-concepts are tied to avoidance of intimacy and decreased trust in human-human interaction (Bartholomew \& Horowitz, 1991; Bowlby, 1979) and possibly decreased satisfaction in human-robot interaction (Dziergwa et al., 2018), which strongly suggests the relevance of the other-concept for interactions. In general, we do not hold the view that every interaction needs or should be filled by intimacy and fueled by trust. We however do want to point out that emotions are increasingly thought to impact any interaction (for reviews, see Kelly \& Barsade, 2001; Van Kleef, 2009), that an interaction partner with a more positive other-concept will likely get more attention (motivated information processing; De Dreu et al., 2006), and that positive attitudes toward collaboration partners (cohesiveness; Lott \& Lott, 1965) influences whether the collaboration is continued (Summers et al., 1988).

What leads to the more positive robot-concepts? Exploratory results suggest that the changes are associated with increased perceived proficiency of the robot collaborator. In other words, how positive a robot was perceived was tied to how helpful it was perceived. That humans form and use beliefs about a robot's capabilities is reasonable and has been shown before (e.g., Weis \& Wiese, 2020). Since a human aid-giver is perceived more negatively when omitting help (Morse, 1972), it is plausible that a collaborator's perceived ability to help should factor in the emotional robot-concept. We thus argue that this exploratory finding strengthens the validity of our initial finding regarding the pre-post adjustments of emotional robot-concepts. Furthermore, in the emotional but not the autonomous condition, the change in the emotional robot-concept was additionally associated with indicators of emotional rather than performancerelated processing. Participants who incorporated the robot more into their self perceived the robot more positively after solving the task together. Furthermore, participants who scored higher in the alexithymia measure were less likely to show such an increase. This exploratory finding suggests that participants did 
believe our framing, i.e. believed that the emotional robot was able to experience feelings, and thus suggests that such a framing is enough to trigger emotional interaction components known to be present in human-human interactions (e.g., self expansion; Aron \& Aron, 1996).

\subsection{Cognitive Offloading}

The present findings suggest that beliefs about and interactions with cognitive environments cannot only alter cognitive self-concepts (Fisher et al., 2015; Hamilton \& Yao, 2018) but also emotional self- and other-concepts. The present findings thereby tie to the current agenda of the $\mathrm{CO}$ community to better delineate consequences of CO (cf. Risko \& Gilbert, 2016). A better understanding of these consequences is crucial for providing well-informed guidance regarding when to engage in and when to omit $\mathrm{CO}$ as well as to inform the design of environments used for $\mathrm{CO}$. We want to use the present findings to emphasize for the CO domain what is already well discussed in the more general human-computer interaction domain (e.g., Lim et al., 2008; Nass \& Reeves, 1996): Interactions with any kind of computers — or even any kind of everyday object (Norman, 2004)—possess emotional components. When trying to explain whether or not people approach a certain CO environment and evaluate its benefit beyond mere task performance, it is likely worthwhile to consider these emotional components. Interestingly, here, the emotional framing of the robot did not alter the amount of offloading, suggesting that beliefs about emotionality might not influence a problem solver's decision whether or not to obtain external help. However, when the identical arithmetic task was provided to participants but participants could choose to receive help from an emotional or an emotionless agent at the same time, participants preferred the emotional agent (Wiese et al., 2021), suggesting that beliefs about emotionality can influence which external help should be recruited if there are several options to choose from. In the bigger picture, we thus suggest that investigating emotionrelated variables like emotional self- and other-concepts or emotion ascriptions could provide a fruitful avenue to increase our understanding of when people engage in $\mathrm{CO}$ and how such engagement could impact the offloader after completion of the $\mathrm{CO}$ interaction. 


\subsection{Conclusion and outlook}

The present study is the first of its kind to show that beliefs about and interactions with telepresent robots can change the emotional concepts of both oneself and a robot interaction partner. The study additionally provides insights into potential underpinnings - alexithymia, inclusion of the robot in the self, perceived competence of the robot—and consequences — mental well-being, cognitive performance —of such change. Future studies are necessary to validate these insights, increase the understanding of the underlying causal structure, and research generalizability to interactions with copresent robots as well as other telepresent and copresent agents. Especially researching the generalizability to interactions with copresent robots seems promising to the authors. Interactions with copresent robots are more engaging than interactions with their telepresent counterparts ( $\mathrm{Li}, 2015)$, which could boost the emotional consequences of the interaction beyond what is reported in the present study for telepresent robots.

\section{$5 \quad$ Highlights}

- Emotional concepts of ourselves and human interaction partners are linked to performance, wellbeing, and interaction style.

- Here, we investigated whether emotional concepts might be equally relevant when interacting with telepresent robot partners.

- Results confirm that beliefs about and interactions with telepresent robots do change emotional concepts of both robot and self.

- Further validation of emotion-driven consequences and investigation of the generalizability to copresent robots is desirable.

- We conclude that emotional consequences for the human should be considered when designing human robot interactions. 


\section{References}

Aron, A., \& Aron, E. N. (1996). Self and self-expansion in relationships. Knowledge Structures in Close Relationships: A Social Psychological Approach, 325-344.

Aron, A., Aron, E. N., Tudor, M., \& Nelson, G. (1991). Close relationships as including other in the self. Journal of Personality and Social Psychology, 60(2), 241-253. https://doi.org/10.1037/00223514.60.2.241

Bagby, R. M., Parker, J. D., \& Taylor, G. J. (1994). The twenty-item Toronto Alexithymia Scale—I. Item selection and cross-validation of the factor structure. Journal of Psychosomatic Research, 38(1), 23-32. https://doi.org/10.1016/0022-3999(94)90005-1

Bartholomew, K., \& Horowitz, L. M. (1991). Attachment styles among young adults: A test of a fourcategory model. Journal of Personality and Social Psychology, 61(2), 226-244. https://doi.org/10.1037/0022-3514.61.2.226

Bartneck, C. (2003). Interacting with an embodied emotional character. Proceedings of the 2003 International Conference on Designing Pleasurable Products and Interfaces, 55-60.

Baumeister, R. F., Stillwell, A. M., \& Heatherton, T. F. (1995). Personal narratives about guilt: Role in action control and interpersonal relationships. Basic and Applied Social Psychology, 17(1-2), 173-198.

Beck, A., Cañamero, L., \& Bard, K. A. (2010). Towards an affect space for robots to display emotional body language. 19th International Symposium in Robot and Human Interactive Communication, 464-469.

Biocca, F. (1997). The cyborg's dilemma: Progressive embodiment in virtual environments. Journal of Computer-Mediated Communication, 3(2), JCMC324.

Bowlby, J. (1979). The making and breaking of affectional bonds. Travistock.

Breazeal, C. (2003). Emotion and sociable humanoid robots. International Journal of Human-Computer Studies, 59(1), 119-155. https://doi.org/10.1016/S1071-5819(03)00018-1 
Breazeal, C., \& Scassellati, B. (1999). How to Build Robots that Make Friends and Influence People. Proceedings of the 1999 IEEE/RSJ International Conference on Intelligent Robots and Systems (IROS99), 858-863.

Clark, A. (1999). An embodied cognitive science? Trends in Cognitive Sciences, 3(9), 345-351.

Cohen, J. (1988). Statistical Power Analysis for the Behavioral Sciences (2nd ed.). Routledge. https://doi.org/10.4324/9780203771587

Dautenhahn, K. (1998). Embodiment and interaction in socially intelligent life-like agents. International Workshop on Computation for Metaphors, Analogy, and Agents, 102-141.

De Dreu, C. K., Beersma, B., Stroebe, K., \& Euwema, M. C. (2006). Motivated information processing, strategic choice, and the quality of negotiated agreement. Journal of Personality and Social Psychology, 90(6), 927.

Diener, E., \& Diener, C. (1996). Most people are happy. Psychological Science, 7(3), 181-185.

Duffy, B. R. (2003). Anthropomorphism and the social robot. Robotics and Autonomous Systems, 42(3-4), 177-190. https://doi.org/10.1016/S0921-8890(02)00374-3

Dziergwa, M., Kaczmarek, M., Kaczmarek, P., Kędzierski, J., \& Wadas-Szydłowska, K. (2018). LongTerm Cohabitation with a Social Robot: A Case Study of the Influence of Human Attachment Patterns. International Journal of Social Robotics, 10(1), 163-176. https://doi.org/10.1007/s12369017-0439-2

Epstein, S. (1973). The self-concept revisited: Or a theory of a theory. American Psychologist, 28(5), 404416. https://doi.org/10.1037/h0034679

Fisher, M., Goddu, M. K., \& Keil, F. C. (2015). Searching for explanations: How the Internet inflates estimates of internal knowledge. Journal of Experimental Psychology: General, 144(3), 674-687. https://doi.org/10.1037/xge0000070

Fox, J., \& Weisberg, S. (2018). An R companion to applied regression. Sage publications.

Fu, W.-T. (2011). A Dynamic Context Model of Interactive Behavior: Cognitive Science. Cognitive Science, 35(5), 874-904. https://doi.org/10.1111/j.1551-6709.2011.01173.x 
Gilbert, S. J. (2015). Strategic use of reminders: Influence of both domain-general and task-specific metacognitive confidence, independent of objective memory ability. Consciousness and Cognition, 33, 245-260. https://doi.org/10.1016/j.concog.2015.01.006

Gray, H. M., Gray, K., \& Wegner, D. M. (2007). Dimensions of mind perception. Science, 315(5812), 619-619.

Gray, W. D., Sims, C. R., Fu, W.-T., \& Schoelles, M. J. (2006). The soft constraints hypothesis: A rational analysis approach to resource allocation for interactive behavior. Psychological Review, 113(3), 461-482. https://doi.org/10.1037/0033-295X.113.3.461

Hamilton, K. A., \& Yao, M. Z. (2018). Blurring boundaries: Effects of device features on metacognitive evaluations. Computers in Human Behavior, 89, 213-220.

Haslam, N. (2006). Dehumanization: An Integrative Review. Personality and Social Psychology Review, 10(3), 252-264. https://doi.org/10.1207/s15327957pspr1003_4

Heatherton, T. F., \& Polivy, J. (1991). Development and validation of a scale for measuring state selfesteem. Journal of Personality and Social Psychology, 60(6), 895.

Hegel, F., Eyssel, F., \& Wrede, B. (2010). The social robot 'flobi': Key concepts of industrial design. 19th International Symposium in Robot and Human Interactive Communication, 107-112.

Herbert, C., Herbert, B. M., Ethofer, T., \& Pauli, P. (2011). His or mine? The time course of self-other discrimination in emotion processing. Social Neuroscience, 6(3), 277-288. https://doi.org/10.1080/17470919.2010.523543

Herbert, C., Herbert, B. M., \& Pauli, P. (2011). Emotional self-reference: Brain structures involved in the processing of words describing one's own emotions. Neuropsychologia, 49(10), 2947-2956. https://doi.org/10.1016/j.neuropsychologia.2011.06.026

Herbert, C., Pauli, P., \& Herbert, B. M. (2011). Self-reference modulates the processing of emotional stimuli in the absence of explicit self-referential appraisal instructions. Social Cognitive and Affective Neuroscience, 6(5), 653-661. https://doi.org/10.1093/scan/nsq082

Hutchins, E. (1995). Cognition in the Wild. MIT press. 
Ifrah, G. (2001). The universal history of computing: From the abacus to the quantum computer. New York : John Wiley. http://archive.org/details/unset0000unse_w3q2

Kelly, J. R., \& Barsade, S. G. (2001). Mood and Emotions in Small Groups and Work Teams. Organizational Behavior and Human Decision Processes, 86(1), 99-130. https://doi.org/10.1006/obhd.2001.2974

Kirsh, D. (2013). Embodied cognition and the magical future of interaction design. ACM Transactions on Computer-Human Interaction, 20(1), 1-30. https://doi.org/10.1145/2442106.2442109

Lakens, D. (2013). Calculating and reporting effect sizes to facilitate cumulative science: A practical primer for t-tests and ANOVAs. Frontiers in Psychology, 4, 863. https://doi.org/10.3389/fpsyg.2013.00863

Li, J. (2015). The benefit of being physically present: A survey of experimental works comparing copresent robots, telepresent robots and virtual agents. International Journal of Human-Computer Studies, 77, 23-37.

Lim, Y., Donaldson, J., Jung, H., Kunz, B., Royer, D., Ramalingam, S., Thirumaran, S., \& Stolterman, E. (2008). Emotional Experience and Interaction Design. In C. Peter \& R. Beale (Eds.), Affect and Emotion in Human-Computer Interaction (Vol. 4868, pp. 116-129). Springer Berlin Heidelberg. https://doi.org/10.1007/978-3-540-85099-1_10

Lott, A. J., \& Lott, B. E. (1965). Group cohesiveness as interpersonal attraction: A review of relationships with antecedent and consequent variables. Psychological Bulletin, 64(4), 259.

Löwe, B., Kroenke, K., \& Gräfe, K. (2005). Detecting and monitoring depression with a two-item questionnaire (PHQ-2). Journal of Psychosomatic Research, 58(2), 163-171.

Lumma, A.-L., Valk, S. L., Böckler, A., Vrtička, P., \& Singer, T. (2018). Change in emotional selfconcept following socio-cognitive training relates to structural plasticity of the prefrontal cortex. Brain and Behavior, 8(4), e00940. https://doi.org/10.1002/brb3.940 
Meixner, F., \& Herbert, C. (2018). Whose emotion is it? Measuring self-other discrimination in romantic relationships during an emotional evaluation paradigm. PLOS ONE, 13(9), e0204106. https://doi.org/10.1371/journal.pone.0204106

Mezulis, A. H., Abramson, L. Y., Hyde, J. S., \& Hankin, B. L. (2004). Is there a universal positivity bias in attributions? A meta-analytic review of individual, developmental, and cultural differences in the self-serving attributional bias. Psychological Bulletin, 130(5), 711. https://doi.org/10.1037/0033-2909.130.5.711

Morse, S. J. (1972). Help, Likability, and Social Influence1. Journal of Applied Social Psychology, 2(1), 34-46. https://doi.org/10.1111/j.1559-1816.1972.tb01262.x

Nash, K., Lea, J. M., Davies, T., \& Yogeeswaran, K. (2018). The bionic blues: Robot rejection lowers self-esteem. Computers in Human Behavior, 78, 59-63. https://doi.org/10.1016/j.chb.2017.09.018

Nass, C., \& Reeves, B. (1996). The media equation: How people treat computers, television, and new media like real people and places. CSLI Publications Stanford.

Norman, D. A. (2004). Emotional Design: Why We Love (or Hate) Everyday Things. Basic Books. https://books.google.de/books/about/Emotional_Design.html?id=z2jvRlqhdlwC\&redir_esc=y

Nosofsky, R. M. (1992). Exemplar-based approach to relating categorization, identification, and recognition. In F. G. Ashby (Ed.), Scientific psychology series. Multidimensional models of perception and cognition (pp. 363-393). Lawrence Erlbaum Associates, Inc.

O’Hara, K. P., \& Payne, S. J. (1998). The Effects of Operator Implementation Cost on Planfulness of Problem Solving and Learning. Cognitive Psychology, 35(1), 34-70. https://doi.org/10.1006/cogp.1997.0676

Pieschl, S. (2019). Will using the Internet to answer knowledge questions increase users' overestimation of their own ability or performance? Media Psychology, 1-27. https://doi.org/10.1080/15213269.2019.1668810

R Core Team. (2013). R: A language and environment for statistical computing. R Foundation for Statistical Computing. 
Risko, E. F., \& Gilbert, S. J. (2016). Cognitive Offloading. Trends in Cognitive Sciences, 20(9), 676-688. https://doi.org/10.1016/j.tics.2016.07.002

Rosenthal-von der Pütten, A. M., Krämer, N. C., \& Herrmann, J. (2018). The Effects of Humanlike and Robot-Specific Affective Nonverbal Behavior on Perception, Emotion, and Behavior. International Journal of Social Robotics, 10(5), 569-582. https://doi.org/10.1007/s12369-018-0466-7

Rosenthal-von der Pütten, A. M., Krämer, N. C., Hoffmann, L., Sobieraj, S., \& Eimler, S. C. (2013). An Experimental Study on Emotional Reactions Towards a Robot. International Journal of Social Robotics, 5(1), 17-34. https://doi.org/10.1007/s12369-012-0173-8

Schroeder, D. A., Graziano, W. G., \& Nadler, A. (2015). The Other Side of Helping. In D. A. Schroeder \& W. G. Graziano (Eds.), The Oxford Handbook of Prosocial Behavior. Oxford University Press. https://doi.org/10.1093/oxfordhb/9780195399813.013.004

Spencer, S. J., Steele, C. M., \& Quinn, D. M. (1999). Stereotype Threat and Women's Math Performance. Journal of Experimental Social Psychology, 35(1), 4-28. https://doi.org/10.1006/jesp.1998.1373

Storm, B. C., Stone, S. M., \& Benjamin, A. S. (2017). Using the Internet to access information inflates future use of the Internet to access other information. Memory, 25(6), 717-723. https://doi.org/10.1080/09658211.2016.1210171

Summers, I., Coffelt, T., \& Horton, R. E. (1988). Work-Group Cohesion. Psychological Reports, 63(2), 627-636. https://doi.org/10.2466/pr0.1988.63.2.627

Tangney, J. P., Wagner, P. E., Hill-Barlow, D., Marschall, D. E., \& Gramzow, R. (1996). Relation of shame and guilt to constructive versus destructive responses to anger across the lifespan. Journal of Personality and Social Psychology, 70(4), 797.

Taylor, S. E., \& Brown, J. D. (1988). Illusion and well-being: A social psychological perspective on mental health. Psychological Bulletin, 103(2), 193-210. https://doi.org/10.1037/0033-2909.103.2.193

Taylor, S. E., \& Brown, J. D. (1994). Positive Illusions and Weil-Being Revisited: Separating Fact From Fiction. Psychological Bulletin, 116(1), 21-27. 
Tessler, R. C., \& Schwartz, S. H. (1972). Help seeking, self-esteem, and achievement motivation: An attributional analysis. Journal of Personality and Social Psychology, 21(3), 318-326. https://doi.org/10.1037/h0032321

Touron, D. R. (2015). Memory avoidance by older adults: When "old dogs" won't perform their “new tricks." Current Directions in Psychological Science, 24(3), 170-176.

Turkle, S. (2012). Alone together: Why we expect more from technology and less from each other. Basic books.

Turkle, S., Taggart, W., Kidd, C. D., \& Dasté, O. (2006). Relational artifacts with children and elders: The complexities of cybercompanionship. Connection Science, 18(4), 347-361.

Van Kleef, G. A. (2009). How emotions regulate social life: The emotions as social information (EASI) model. Current Directions in Psychological Science, 18(3), 184-188.

Võ, M. L., Conrad, M., Kuchinke, L., Urton, K., Hofmann, M. J., \& Jacobs, A. M. (2009). The Berlin affective word list reloaded (BAWL-R). Behavior Research Methods, 41(2), 534-538. https://doi.org/10.3758/BRM.41.2.534

Watson, L. A., Dritschel, B., Obonsawin, M. C., \& Jentzsch, I. (2007). Seeing yourself in a positive light: Brain correlates of the self-positivity bias. Brain Research, 1152, 106-110. https://doi.org/10.1016/j.brainres.2007.03.049

Waytz, A., Gray, K., Epley, N., \& Wegner, D. M. (2010). Causes and consequences of mind perception. Trends in Cognitive Sciences, 14(8), 383-388.

Weis, P. P., \& Herbert, C. (2017). Bodily Reactions to Emotional Words Referring to Own versus Other People's Emotions. Frontiers in Psychology, 8(1277).

Weis, P. P., \& Wiese, E. (2019). Problem Solvers Adjust Cognitive Offloading Based on Performance Goals. Cognitive Science, 43(e12802), 20. https://doi.org/10.1111/cogs.12802

Weis, P. P., \& Wiese, E. (2020). Know Your Cognitive Environment! Mental Models as Crucial Determinant of Offloading Preferences: Human Factors. https://doi.org/10.1177/0018720820956861 
Wickham, H., Averick, M., Bryan, J., Chang, W., McGowan, L. D., François, R., Grolemund, G., Hayes, A., Henry, L., \& Hester, J. (2019). Welcome to the Tidyverse. Journal of Open Source Software, 4(43), 1686.

Wiese, E., Metta, G., \& Wykowska, A. (2017). Robots as intentional agents: Using neuroscientific methods to make robots appear more social. Frontiers in Psychology, 8, 1663.

Wiese, E., Weis, P. P., Bigman, Y., Kapsaskis, K., \& Gray, K. (2021). It's a match: Task assignment in human-robot collaboration depends on mind perception. International Journal of Social Robotics, in press.

Wiese, E., Wykowska, A., Zwickel, J., \& Müller, H. J. (2012). I See What You Mean: How Attentional Selection Is Shaped by Ascribing Intentions to Others. PLoS ONE, 7(9), e45391. https://doi.org/10.1371/journal.pone.0045391

Winter, D., Herbert, C., Koplin, K., Schmahl, C., Bohus, M., \& Lis, S. (2015). Negative Evaluation Bias for Positive Self-Referential Information in Borderline Personality Disorder. PLOS ONE, 1O(1), e0117083. https://doi.org/10.1371/journal.pone.0117083 


\section{Supplemental material}

\subsection{Words extracted from BAWL-R}

\section{Table S1}

Word stimuli for the word evaluation task

\begin{tabular}{|c|c|c|c|c|c|}
\hline word (German) & word (English) & $\begin{array}{l}\text { valence } \\
\text { (German) }\end{array}$ & $\begin{array}{l}\text { valence } \\
\text { (English) }\end{array}$ & $\begin{array}{l}\text { imageability } \\
\text { (German) }\end{array}$ & $\begin{array}{l}\text { imageability } \\
\text { (English) }\end{array}$ \\
\hline SIEG & VICTORY & 2.20 & 1.97 & 4.44 & 6.07 \\
\hline ZUKUNFT & FUTURE & 2.20 & 1.57 & 2.78 & 5.00 \\
\hline GEWINN & PROFIT & 2.10 & 1.53 & 3.14 & 5.47 \\
\hline TRIUMPH & TRIUMPH & 2.00 & 2.10 & 4.22 & 5.93 \\
\hline ENERGIE & ENERGY & 2.10 & 1.67 & 3.44 & 5.43 \\
\hline AKTIVITÄT & ACTIVITY & 1.71 & 1.40 & 4.12 & 5.37 \\
\hline ERFOLG & ACHIEVEMENT & 2.10 & 2.00 & 3.05 & 5.37 \\
\hline WISSEN & KNOWLEDGE & 2.03 & 2.13 & 2.62 & 5.43 \\
\hline BEDEUTUNG & SIGNIFICANCE & 0.94 & 1.67 & 1.81 & 4.50 \\
\hline EXISTENZ & EXISTENCE & 1.60 & 1.40 & 2.00 & 5.23 \\
\hline CHANCE & OPPORTUNITY & 2.10 & 1.63 & 2.22 & 5.17 \\
\hline TREFFER & SUCCESS & 1.90 & 2.20 & 5.00 & 5.53 \\
\hline RÜCKKEHR & RETURN & 1.35 & 0.63 & 4.35 & 4.30 \\
\hline LEISTUNG & PERFORMANCE & 1.80 & 1.47 & 2.33 & 5.23 \\
\hline FÄHIGKEIT & ABILITY & 1.62 & 1.60 & 2.12 & 5.03 \\
\hline KRAFT & POWER & 1.38 & 1.30 & 3.85 & 5.33 \\
\hline STÄRKE & STRENGTH & 1.79 & 1.97 & 3.85 & 5.93 \\
\hline ERGEBNIS & SCORE & 0.74 & 1.33 & 3.08 & 5.43 \\
\hline BEGEGNUNG & ENCOUNTER & 1.56 & 0.83 & 4.85 & 5.50 \\
\hline KONTAKT & CONTACT & 1.40 & 1.13 & 3.44 & 5.80 \\
\hline TÄTIGKEIT & AGENCY & 0.74 & 0.80 & 2.92 & 4.83 \\
\hline VORTEIL & ADVANTAGE & 1.80 & 1.57 & 1.89 & 4.80 \\
\hline ANTWORT & RESPONSE & 0.94 & 1.33 & 2.69 & 4.80 \\
\hline MISSION & MISSION & 0.90 & 1.40 & 2.78 & 5.23 \\
\hline WERT & VALUE & 1.06 & 1.70 & 2.73 & 5.00 \\
\hline LÖSUNG & SOLUTION & 1.53 & 1.87 & 2.73 & 5.53 \\
\hline TEILNAHME & PARTICIPATION & 0.82 & 1.40 & 2.96 & 5.37 \\
\hline LOGIK & LOGIC & 1.15 & 1.70 & 2.59 & 4.90 \\
\hline QUALITÄT & QUALITY & 1.65 & 1.70 & 2.42 & 5.40 \\
\hline AUSDAUER & ENDURANCE & 1.60 & 1.63 & 3.22 & 5.23 \\
\hline SCHUTZ & PROTECTION & 1.70 & 1.63 & 3.67 & 5.20 \\
\hline \multirow[t]{2}{*}{ PAUSE } & BREAK & 1.15 & 0.20 & 3.00 & 5.70 \\
\hline & & 1.55 & 1.51 & 3.13 & 5.28 \\
\hline
\end{tabular}

Note. Ratings are for the German words only and extracted from BAWL-R (Võ et al., 2009). Valence was rated on a scale from -3 to 3 , imageability on a scale from 1 to 7 . For details on the word selection procedure, see section Word evaluation task of the main manuscript. 


\subsection{Proficiency ratings}

\section{Figure S1}

Proficiency Rating Changes From Pre- to Post-Manipulation

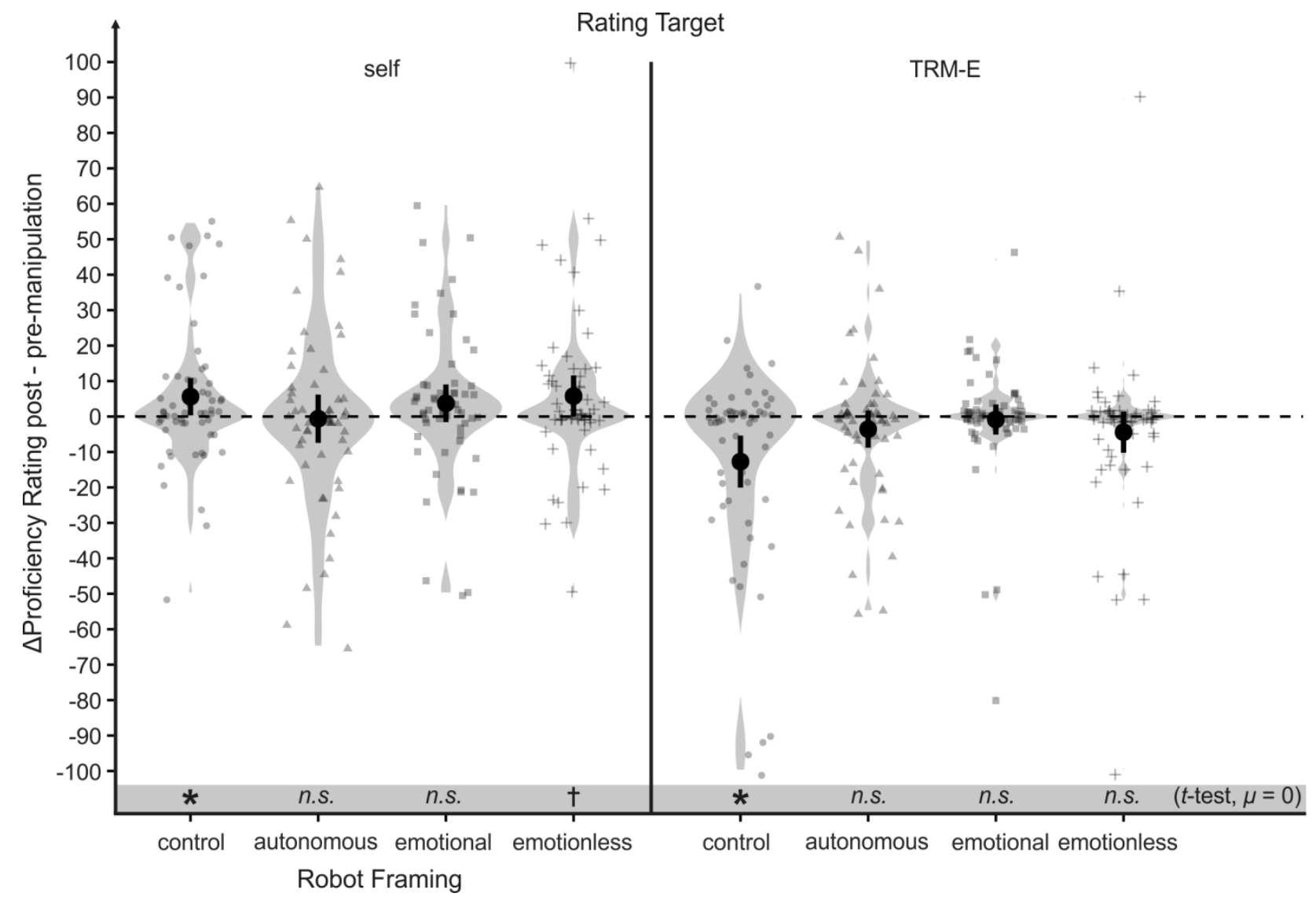

Note. Error bars indicate 95\% CI. *: $p<.05, t: p=.06$, n.s.: $p>.14$ 